IZA DP No. 5631

The Impact of Active Labour Market Policy on

Post-Unemployment Outcomes:

Evidence from a Social Experiment in Denmark

Sylvie Blasco

Michael Rosholm

April 2011 


\title{
The Impact of Active Labour Market Policy on Post-Unemployment Outcomes: Evidence from a Social Experiment in Denmark
}

\author{
Sylvie Blasco \\ Aarhus University, CIM and IZA \\ Michael Rosholm \\ Aarhus University, CIM and IZA \\ Discussion Paper No. 5631 \\ April 2011 \\ IZA \\ P.O. Box 7240 \\ 53072 Bonn \\ Germany \\ Phone: +49-228-3894-0 \\ Fax: +49-228-3894-180 \\ E-mail: iza@iza.org
}

\begin{abstract}
Any opinions expressed here are those of the author(s) and not those of IZA. Research published in this series may include views on policy, but the institute itself takes no institutional policy positions.

The Institute for the Study of Labor (IZA) in Bonn is a local and virtual international research center and a place of communication between science, politics and business. IZA is an independent nonprofit organization supported by Deutsche Post Foundation. The center is associated with the University of Bonn and offers a stimulating research environment through its international network, workshops and conferences, data service, project support, research visits and doctoral program. IZA engages in (i) original and internationally competitive research in all fields of labor economics, (ii) development of policy concepts, and (iii) dissemination of research results and concepts to the interested public.
\end{abstract}

IZA Discussion Papers often represent preliminary work and are circulated to encourage discussion. Citation of such a paper should account for its provisional character. A revised version may be available directly from the author. 


\section{ABSTRACT \\ The Impact of Active Labour Market Policy on Post-Unemployment Outcomes: Evidence from a Social Experiment in Denmark ${ }^{*}$}

While job search theory predicts that active labour market policies (ALMPs) can affect postunemployment outcomes, empirical evaluations investigating transition rates have mostly focused on the impact of ALMPs on exit rates from the current unemployment spell. We use a social experiment, which was conducted in Denmark in 2005-6, to investigate the effects of a dramatic intensification of ALMPs on reemployment stability. We investigate the nature of this impact. We estimate a duration model with lagged duration dependence to separately identify "indirect" (via shorter unemployment duration) and "direct" (through a more efficient matching process) effects of ALMPs on subsequent employment duration. We find that overall intensive activation significantly reduces unemployment recurrence for men, but not for women. When we control for dynamic selection into employment and lagged duration dependence, the positive impact of the treatment becomes smaller but remains significant. $80 \%$ of the global impact of intensification acts through the direct channel for men.

JEL Classification: J64, C21, C41, J68

Keywords: $\quad$ social experiment, labour market policy regime, treatment effect, post-unemployment outcome, duration model, lagged duration dependence, dynamic selection

Corresponding author:

Michael Rosholm

Department of Economics and CIM

Aarhus School of Business, Aarhus University

Hermodsvej 22

DK-8230 Aabyhøj

Denmark

E-mail: rom@asb.dk

\footnotetext{
* The authors thank the participants of ESPE 2010, EALE/SOLE 2010, EEA 2010, the 2nd Meeting of Danish Microeconometrics Network, ELE Summer Institute, and NCoE workshop on active labour market policies and family friendly policies. We are grateful to the National Labour Market Board for access to the data, and to the Ministry of Employment for partly financing this research via a grant to CAFE - Centre for Research in Active Labour Market Policy Effects.
} 


\section{Introduction}

This paper evaluates the immediate and post-unemployment effects of intensive active labour market policies based on data from a social experiment conducted in Denmark. This experiment, which consisted of an intensification in several dimensions of active labour market policies, has shown remarkable effects on the exit rate from unemployment. We investigate whether the experiment has an impact beyond the first unemployment spell. We measure the impact of intensive activation on reemployment stability and decompose the nature of this potential impact into a direct and an indirect effect. The indirect effect goes via lagged duration dependence - the treated find jobs faster, and short lagged unemployment duration leads to longer employment duration - while the direct effect presumably acts via the parameters of the search process.

Empirical evaluations of active labour market policies (ALMPs) have often focused on how programme participation affects exit rates from the current unemployment spell, or on employment status and/or earnings a short period after the start of the programme (see the meta-analysis by Kluve [2010] and Card et al. [2010]). Most of these studies find small and in some cases even unfavourable effects of programme participation on transition rates into employment and/or on earnings, see e.g. the reviews by Heckman et al. [1999], Kluve and Schmidt [2002], and Kluve [2006]. It is often posited that these disappointing results arise because a positive post-participation effect - i.e an increase in employment rates, earnings, or transition rates into employment after completed programme participation - is dominated by a negative lock-in effect (Crépon et al. [2005], Munch and Skipper [2005]) - i.e. a reduced transition rate into employment, reduced employment rates and/or earnings during programme participation.

Recently, probably to some extent as a consequence of the disappointing programme participation effects, focus has switched towards studying the effects of alternative labour market instruments such as 'threat effects' of perceived future programme participation, monitoring and sanction policies, job search assistance, meetings and the contribution of the case worker, see the review in section 2.4. These instruments tend to show more favourable effects, suggesting that the successful active labour market policy consists of a (coherent) set of several instruments.

However, it might be that the effects of participation in activation programmes - or active labour market policies in general - lie not so much in a reduction of current unemployment duration but rather in improving postunemployment outcomes. Job search theory as well as common sense indeed suggest that participation in ALMPs could have positive longer-term effects that could offset or enlarge these short-term effects.

There exist a number of studies using matching techniques, which analyze longer-term effects of policies, see the literature review in section 2.4. There are very few studies which investigate policy effects on post-unemployment outcomes using a duration model framework. An important reason for this is probably the difficulties in separating the combined effects of selection into treatment 
and selection into employment from treatment effects on e.g. employment duration. Yet, the potential gain from such an analysis is a richer understanding of the nature of the effects found in many matching studies.

Our analysis is based on data from a social experiment, hence, since we are interested in the overall intention-to-treat effect, selection into treatment is not an issue. In this case, the selection problem is reduced to modeling selection into employment. We want to determine whether post-unemployment impacts stem from shorter unemployment spells (the indirect effect) or from an improvement of the search technology (the direct effect). We therefore estimate treatment effects in a joint model of unemployment and subsequent employment durations, allowing for lagged duration dependence. We find that participation in the experiment leads to a dramatic reduction in unemployment duration, a result also found by Graversen and van Ours [2008] and Rosholm [2008], see the next section. Moreover, we find that, for men, participation in the experiment lengthens subsequent employment duration by almost 10 per cent, while we find no effect for women. A decomposition of this effect suggests that about 20-25 per cent of it is due to lagged duration dependence - participation reduces unemployment duration, and short unemployment duration leads to longer employment duration. The rest is a 'true' or 'direct' treatment effect of the interventions implied by the experiment.

A so-called threat-effect has been shown to be a major driving force for accelerated exits from unemployment (see e.g. Black et al. [2003]); individuals facing a more intensive treatment are more likely to leave unemployment faster if they dislike having to spend more time in programmes, or having their search efforts monitored, etc. Theory would predict that compulsion would have a negative impact on post-unemployment outcomes, while actual participation would increase the quality of reemployment (van Ours [2007]). Hence, the actual sign of the treatment effect on post-unemployment employment duration is an empirical matter.

The rest of the paper is organised as follows. In the next section, we present the experiment, some previous results using data from the same experiment, and some relevant literature and its relation to these findings, in order to set the stage. In section 3 , we present a simple search model in order to establish a framework for interpreting the effects of the experiment. The model implies that participation in the experiment may lead to shorter or longer subsequent employment duration depending on the dominant channel through which the experiment affects individual behaviour. In section 4 we present the data, while the econometric analysis is outlined in section 5. Results are presented and discussed within the theoretical framework in section 6 , where we also perform the decomposition of the effect into a direct effect and an indirect effect operating via lagged duration dependence. Finally, some conclusions and issues for further studies are offered in section 7 . 


\section{The social experiment}

In this section, we first describe the experiment, then we briefly review earlier results using data from the experiment, and finally we relate these results and the experiment to a selective subset of the relevant literature.

\subsection{The experiment}

The randomized experiment was conducted in two Danish counties, Storstrøm County and Southern Jutland County. Its aim was to assess the impact of an intensification of labour market policies on the exit rates from unemployment for unemployment insurance (UI) benefit recipients.

Workers eligible for UI benefits who entered unemployment during the fourmonth period between the start of November 2005 and the end of February 2006 were randomly assigned into a treatment and a control group based on their date of birth in the month. Those born on the $1^{\text {st }}$ to the $15^{\text {th }}$ were assigned to the treatment group, while those born on the $16^{\text {th }}$ to the $31^{\text {st }}$ were assigned to the control group. This was not known in advance, and there was no advance public discussion of the existence of the experiment.

Persons in the treatment group were given the following treatment:

1. After approximately 1 week in open unemployment they received a letter informing them that they are taking part in a 'pilot study' regarding a new labour market policy regime. They are also informed about the contents of the new labour market policy regime, which is described in the next points.

2. After 5-6 weeks of unemployment, they should participate in a two-week Job Search Assistance (JSA) programme.

3. Thereafter, ideally from the 7 th to the 18 th week of unemployment, they should meet frequently with a case worker in order to ensure that they are searching actively and in order to assist them in their job search. In the county of Southern Jutland, meetings should take place once every fortnight, while in the county of Storstrøm meetings should take place each week.

4. Those who have not found employment after 18 weeks of unemployment would have to participate in an unspecified programme for 13 weeks minimum duration. The 4 types of programmes workers could be allocated to were: 'private sector temporary employment subsidy jobs' ( 6 months), temporary employment within the public sector (6-12 months), classroom training programmes (the majority of programmes being shorter than 13 weeks) and vocational training programmes in firms (a few months).

5. Those who were still unemployed at the end of the programme were then ending the experimental treatment and did, for the remaining time in unemployment, receive the same type of treatments as those administered to the control 
group. That is, the treatment intensity went 'back to normal'.

Individuals could not escape treatment by leaving unemployment for a short period: if they returned to unemployment during the period of the experiment, they re-entered the experiment at the stage where they left it.

Persons in the control group were subjected to the standard labour market policy, implying that they should attend meetings with case workers once every 13 weeks, and after one year of unemployment they were required to participate in an unspecified programme lasting at least one week. The time span between programmes should hereafter be shorter than six months.

In both the treatment and control groups, unemployed workers would have to attend a $\mathrm{CV} /$ basic registration meeting within 4 weeks after becoming unemployed. Figure 3 in the Appendix shows the timing in terms of unemployment duration for the treatment and control groups over the intended period of treatment, which is approximately 30 weeks.

\subsection{Implementation}

Although the treatment appears to be quite precisely defined, there is still some scope for discretion by region and by caseworker in the contents of the JSA course and the meetings, and in the type of activation programmes offered. Moreover, Rosholm [2008] shows that in general the realized actual treatment intensities (of JSA courses, meetings, and activation programmes) were not nearly as large as the intended treatment, and it was often given later than was intended. Still, there was a considerable difference in weekly meeting rates and activation rates of 20-40 \% (cf. Figure 4) between treatments and controls in most of the first 30 weeks of unemployment duration (the experimental period).

\subsection{Previous results using data from the same experiment}

Graversen and van Ours [2008] and Rosholm [2008] find that, on average, individuals in the treatment group leave unemployment for employment considerably (i.e. around $20 \%$ ) faster than individuals in the control group. The information letter, the more intensive assignment to JSA courses, to meetings and to activation programmes thus have the combined effect of increasing job finding rates.

Further analyses suggest that a significant part of the increase in exit rates comes from a 'threat-effect': Rosholm [2008] finds that, when controlling for treatment group status as well as time-varying indicators for the various specific treatments actually prescribed to the unemployed workers, it appears that none of the specific treatments have positive effects during or after participation. Some of them even have large negative effects, suggesting that lock-in effects are present. In other words, controlling for actual treatments prescribed earlier in the spell does not remove the effect of belonging to the treatment group. This implies that participation in the experiment affects individual behaviour mostly 
before an actual treatment is supposed to begin. He subsequently estimates a reduced-form econometric model confirming the presence of these threat-effects.

Graversen and van Ours [2009] investigate more precisely the existence of transaction costs associated with participation in active programmes. They use the distance from the agency to proxy for these costs. They find that unemployed workers who live far from the place where the activation programme is administered experience more positive effects of the experiments than individuals living closer to training sites. They conclude that activation programmes are mostly effective because the unemployed do not like them.

\subsection{Perspectivation to selective literature}

There are several components in our experiment, each of which may have a different impact on job search behaviours and success. Reviewing the growing number of empirical evaluations of ALMPs that consider reemployment quality as an outcome variable ${ }^{1}$, it appears that the estimated impact of programme participation on employment duration differs by country, by the type of programme evaluated, and by the participants' characteristics ${ }^{2}$.

The information letter sent to individuals in the treatment group opens for the possibility of a 'threat-effect': the moment an unemployed worker realizes that there is a positive risk of having to participate in a programme in the future, he increases his job search intensity or reduces his reservation wage to avoid programme participation. Evidence of a substantial threat-effect, especially among the more employable, has been found in Denmark as well as in other countries (see Hägglund [2006] for Sweden, Black et al. [2003] for the US, Cockx and Dejemeppe [2007] for Belgium). In Denmark, Rosholm and Svarer [2008], Geerdsen and Holm [2007] and Geerdsen [2006] show, using different identification strategies, that having to participate in a programme significantly reduces the average unemployment duration. The presence of a substantial threat-effect is likely to affect post-unemployment outcomes because it changes the propensity of the job seeker to accept low-quality jobs. However, we are not aware of any studies that have investigated the consequences of having found employment due to a threat-effect on reemployment stability. Black et al. [2003] find no detrimental impact of notification to treatment on reemployment wage. Moreover, the fact that some treated exit unemployment once they are notified of the experiment means that there exists a dynamic selection into actual treatment.

A crucial component behind the threat-effect is supposedly the risk of being monitored and of being sanctioned in the case of non-compliance. Indeed, Cockx and Dejemeppe [2007] find that the threat-effect is less important when

\footnotetext{
${ }^{1}$ See Ehrenberg and Oaxaca [1976], Addison et al. [2000], Belzil [2001], Tatsiramos [2006], Card et al. [2007], Van Ours and Vodopivec [2008], Lalive [2007] for effects of unemployment benefits on subsequent job match or wages.

${ }^{2}$ As for post-unemployment wages, the literature unanimously reports insignificant or negative impact of programme participation (Klepinger et al. [2002], Black et al. [2003], Munch and Skipper [2005], Larsson [2003], Addison and Portugal [2002]).
} 
monitoring is combined with job search assistance. In France, where the risk of sanction is low, there are no such threat effects (Blasco [2010] and Crépon et al. [2010]). The literature almost unanimously documents very large effects of monitoring and sanction policies on the exit rates out of unemployment (see e.g. Lalive et al. [2005] and Svarer [2010]). In terms of longer-term consequences of monitoring and sanction policies, the sparse empirical evidence is unanimous and in accordance with the theoretical predictions, according to which monitoring and sanctions would worsen post-unemployment outcomes: van den Berg and Vikström [2009] find, using Swedish data, that sanctions cause a permanent decline in subsequent wages of around $4 \%$ and reduces the number of hours worked. Arni et al. [2009] investigate the effects of warnings and sanctions in the Swiss labour market and also find strong negative effects of warnings and sanctions on wages, shorter employment duration, and increasing labour market exit rates.

Another important element of the experiment is the counseling element in the JSA courses as well as in meetings with case workers. This type of programme aims at improving job search skills and at improving the employer-employee matching process. Hence it could improve subsequent job stability. Crépon et al. [2005] evaluate the effects of intensive counseling schemes administered to French unemployed workers. Some of these schemes significantly reduce unemployment duration, but they mostly improve the match quality in the sense that the time until unemployment recurrence is prolonged. Conversely, participation in counseling and job search assistance schemes lead to shorter jobs in Portugal (Addison and Portugal [2002]). Klepinger et al. [2002] find small or insignificant treatment effects on the quality of post-unemployment jobs. The timing of treatment matters: using a randomized experiment, Dolton and O'Neil [2002] find that in the UK, the Restart interviews reduced the male unemployment rate five years later, as compared to a control group for whom participation took place six months later. There is a related literature, which investigates the importance of the case worker, and Behncke et al. [2010] find that case workers who are less concerned with obtaining a 'cooperative and harmonic relationship with their clients' increase the clients' employment chances. A possible explanation is that tough case workers lead to threat-effects. No existing studies though investigate the role of the case workers on reemployment quality.

The last main component of the experiment is activation programmes that aim at improving participants' qualifications. They may lead to less favourable outcomes in the short-term due to so-called lock-in effects: the learning of new skills takes time and this time is therefore not available for job search, see the references mentioned in the introduction for examples and overviews. On the other hand, activation programmes could improve subsequent job stability due to a better employer-employee match and a lower unemployment recurrence and give access to better paid jobs due to the accumulation of human capital through the programme, and/or affect occupation if participants acquire new and specific skills. For Denmark, Munch and Skipper [2005] find that subsidized employment schemes in the private sector increase post-unemployment 
job duration, while the opposite is the case for subsidized employment schemes in the public sector. They also show that only youth benefit from ordinary classroom training programmes in terms of employment duration. The matching literature reports that the effects of participation on training programmes improve over time and that for some types of programmes, effects even switch from significantly negative in the short run to significantly positive 2 to 4 years after participation (Lechner and Wunsch [2006], Lechner and Wiehler [2010] for Austria, Lechner et al. [2010] for West-Germany and Sianesi [2008] for Sweden).

Thus, the post-unemployment impacts of intensive active labour market policies are both theoretically and empirically undetermined. On the one hand, we may expect that ALMPs reduce employment duration (and/or lowers earnings) if individuals are pushed into low-quality jobs following actual or perceived sanctions or perceived future programme participation (van Ours [2007]). On the other hand, activation programmes and job search assistance could lead to better job matches and hence longer employment duration and higher earnings. Moreover, the reduction in unemployment duration that these policies (might) produce, could by itself lead to longer employment duration if there is lagged duration dependence. Besides, if compulsion and monitoring and sanctions lower the value of the current unemployment spell, it also makes future unemployment spells less valuable, so that it creates incentives to unemployed workers to find stable reemployment.

More generally, ALMPs affect the job search strategies of job seeks. For instance, van den Berg and van der Klaauw [2006] show that increasing monitoring leads to a shift from informal to formal job search, which again may affect the quality of post-unemployment outcomes, although the sign of the effect is not obvious. We therefore turn to the construction of a theoretical framework for understanding and analyzing the impact of our experiment.

\section{A simple illustrative job search model}

To illustrate how a set of intensive active labour market policies may affect unemployment and particularly subsequent employment duration, we construct a simple job search model with two types of jobs - 'good' and 'bad' - and endogenous job-type specific search intensities. Arni et al. [2009] proposed a similar model to investigate the impact of sanctions on the quality of postunemployment jobs. ${ }^{3}$ They assume that offers obtained through each of the two search channels carry different job destruction rates. Moreover, they assume that treatment does not occur immediately, so to account for possible ex ante effects they distinguish between several unemployment states, one before, one

\footnotetext{
${ }^{3}$ van den Berg and van der Klaauw [2006] develop a job search model with two search channels and endogenous search intensity to predict the impact of counseling and monitoring on unemployment durations. They distinguish between a formal and an informal search channel. In their model, counseling and monitoring only affect the job offer arrival rate in the formal channel. They assume that jobs last forever, but their results are robust to job destruction.
} 
during, and one after treatment. They define the optimal channel-specific search intensities in each of the unemployment states they distinguish.

Our setup is somewhat different, but in the same spirit as that of Arni et al. [2009]; as we have an experiment where the treatment starts immediately (with the receipt of the information letter), we do not distinguish between $e x$ ante and ex post effects of participation in treatment. Instead, we allow for a threat effect indirectly by allowing treatment to affect the sanction rate.

In our framework, there are two states of the world; one with intensive active labour market policies, the treatment state (denoted state 1), and one with less intensive (standard) ALMPs, the control state (denoted state 0 ). Let the values of unemployment in the two states be $V_{1}$ and $V_{0}$, respectively. There are two types of jobs, good jobs and bad jobs, distinguished by their job destruction rate, $\delta_{g}<\delta_{b}$. We assume these to be exogenous. Both types of jobs pay the same wage, $w$.

The flow utility while unemployed is $\underline{b}$, which may be thought of as UI benefits. We denote $u_{l}$ the utility of leisure.

The individual invests flow effort $s_{i}$ in the search for a job through channel $i$. Search is costly: for an effort $s_{i} \geq 0$, the individual pays $c_{i}\left(s_{i}\right)$ at each period with $c_{i}()>0,. c_{i}^{\prime}()>0,. c_{i}^{\prime \prime}()>$.0 and $c_{i}(0)=0$. For numerical simplicity, we assume $c_{i}(s)=\frac{1}{2} c_{i} s^{2}$. The individual receives job offers from both channels. Offers of bad jobs arrive with rate $s_{b} \lambda_{b}$.

The offer arrival rate for good jobs depends on both search intensity and on the state of the world; in the treatment state, search technology is $\lambda_{g 1}$, and in the untreated state, it is $\lambda_{g 0}$. For now, we assume that $\lambda_{g 1}>\lambda_{g 0}$. That is, the treatment improves the search technology for good jobs only. ${ }^{4}$ This reflects the perceived positive impacts of JSA courses, the counseling efforts of case workers during meetings with the clients, and the skill enhancing features of activation programmes.

There is an additional effect of the treatment; namely, it leads to increased monitoring, and thus, to an increase in the probability of being sanctioned. Without loss of generality, we take the sanction rate to be 0 in the control state and $\gamma$ in the treated state. A sanction reduces $\underline{b}$. For simplicity, we take $\underline{b}=0$ in the remainder of the unemployment spell in the case of a sanction. Hence, there are potentially positive and negative effects of the treatment; the increase in the offer arrival rate for good jobs may lead to shorter unemployment duration and longer lasting jobs, while the possibility of being sanctioned lowers the value of being unemployed, thus also shortening unemployment duration, but with an unclear effect on subsequent employment duration.

The discount rate is $\rho$.

The value of being employed in a job of type $i(i=\{b, g\})$ obtained from the $t$-state-of-the-world unemployment $(t=\{0,1\})$ is:

$$
\rho J_{i t}=w+\delta_{i}\left(V_{t}-J_{i t}\right)
$$

\footnotetext{
${ }^{4}$ The reversal of this assumption is briefly discussed later in this section.
} 
In the control state, the value of being unemployed is:

$$
\rho V_{0}=\underline{b}+u_{l}-c_{b 0}\left(s_{b}\right)-c_{g 0}\left(s_{g}\right)+s_{g} \lambda_{g 0}\left(J_{g 0}-V_{0}\right)+s_{b} \lambda_{b 0}\left(J_{b 0}-V_{0}\right)
$$

The first order conditions give us the optimal search intensities, $s_{b 0}^{*}$ and $s_{g 0}^{*}$ :

$$
s_{b 0}^{*}=\frac{\lambda_{b 0}}{c_{b}}\left(J_{b 0}-V_{0}\right) \text { and } s_{g 0}^{*}=\frac{\lambda_{g 0}}{c_{g}}\left(J_{g 0}-V_{0}\right)
$$

Inserting for the values of the job, we find

$$
s_{b 0}^{*}=\frac{\lambda_{b 0}}{c_{b}} \frac{\left(w-\rho V_{0}\right)}{\rho+\delta_{b}} \text { and } s_{g 0}^{*}=\frac{\lambda_{g 0}}{c_{g}} \frac{\left(w-\rho V_{0}\right)}{\rho+\delta_{g}}
$$

The treatment state differs from the control state in two important respects, as mentioned above; first, individuals in the treatment state are monitored more closely and are therefore more likely to be sanctioned. Second, individuals in the treatment state receive more counseling and more training in the form of activation programmes. This affects the offer arrival rate of good jobs denoted $\lambda_{g 1}$.

Hence, the value of unemployment in the treatment state is:

$\rho V_{1}=\underline{b}+u_{l}-c_{b 1}\left(s_{b}\right)-c_{g 1}\left(s_{g}\right)+s_{g} \lambda_{g 1}\left(J_{g 1}-V_{1}\right)+s_{b} \lambda_{b 0}\left(J_{b 1}-V_{1}\right)+\gamma\left(V_{s}-V_{1}\right)$,

where $V_{s}$ is the value of being unemployed and sanctioned (in state 1):

$$
\rho V_{s}=u_{l}-c_{b 1}\left(s_{b}\right)-c_{g 1}\left(s_{g}\right)+s_{g} \lambda_{g 1}\left(J_{g 1}-V_{1}\right)+s_{b} \lambda_{b 0}\left(J_{b 1}-V_{1}\right),
$$

where we have assumed that accepting a job gives you a clean sheet; if you return to unemployment, you are no longer sanctioned.

Once again, the first order conditions give the optimal search intensities $s_{b 1}^{*}$ and $s_{g 1}^{*}$ defined as follows:

$$
s_{b 1}^{*}=\frac{\lambda_{b 0}}{c_{b}}\left(J_{b 1}-V_{1}\right) \text { and } s_{g 1}^{*}=\frac{\lambda_{g 1}}{c_{g}}\left(J_{g 1}-V_{1}\right)
$$

Substituting once again for the values of a job, we find

$$
s_{b 1}^{*}=\frac{\lambda_{b 0}}{c_{b}} \frac{\left(w-\rho V_{1}\right)}{\rho+\delta_{g}} \text { and } s_{g 1}^{*}=\frac{\lambda_{g 1}}{c_{g}} \frac{\left(w-\rho V_{1}\right)}{\rho+\delta_{g}}
$$

As pointed out by van den Berg and van der Klaauw [2006], we cannot identify separately changes in search costs and in job arrival rates. This is why we set $c_{i 0}=c_{i 1}=c_{i}$ for $i=\{b, g\}$. 


\subsection{The effect of treatment}

The first thing to note is that the treatment may increase or decrease the search intensity for bad jobs, depending on whether the value of unemployment decreases or increases;

$$
\begin{aligned}
\frac{s_{b 0}^{*}}{s_{b 1}^{*}} & =\frac{\frac{\lambda_{b 0}}{c_{b}} \frac{\left(w-\rho V_{0}\right)}{\rho+\delta_{b}}}{\frac{\lambda_{b 0}}{c_{b}} \frac{\left(w-\rho V_{1}\right)}{\rho+\delta_{b}}} \\
& =\frac{w-\rho V_{0}}{w-\rho V_{1}},
\end{aligned}
$$

implying that the search intensity for bad jobs increases with treatment if the sanction (or its probability) is large enough to offset the increase in the value function arising from the increase in $\lambda_{g 1}$.

The ratio between the search intensity for good jobs in the control and treatment states is

$$
\begin{gathered}
\frac{s_{g 0}^{*}}{s_{g 1}^{*}}=\frac{\frac{\lambda_{g 0}}{c_{g}} \frac{\left(w-\rho V_{0}\right)}{\rho+\delta_{g}}}{\frac{\lambda_{g 1}}{c_{g}} \frac{\left(w-\rho V_{1}\right)}{\rho+\delta_{g}}} \\
=\frac{\lambda_{g 0}}{\lambda_{g 1}} \frac{w-\rho V_{0}}{w-\rho V_{1}},
\end{gathered}
$$

which may also be either above or below 1 . However,

$$
\frac{s_{b 0}^{*}}{s_{b 1}^{*}} / \frac{s_{g 0}^{*}}{s_{g 1}^{*}}=\frac{\lambda_{g 1}}{\lambda_{g 0}}>1,
$$

so the treatment does imply a relative switch in search activity towards good jobs in this case, where treatment improves search technology for good jobs.

Were the opposite the case, that is, if treatment increases the basic search efficiency for bad jobs, then we would find something similar to a standard threat effect, namely that individuals in the treatment state would increase their search intensity for bad jobs more, hence increasing the fraction of workers in bad jobs and reducing the observed employment duration (and thus increasing unemployment recurrence).

In a model with just one search channel, but where a job offer implies a draw from a wage distribution, an increase in search effectiveness would increase the reservation wage and hence partially offset the fall in unemployment duration induced by the increase in the offer arrival rate, while average accepted wages would increase. Working in the opposite direction, a sanction would lower the value of unemployment and hence reservation wages, which would tend to once again reduce unemployment duration but lower average accepted wages as was observed by Arni et al. [2009].

We now briefly discuss how a treatment effect on subsequent employment duration may occur via lagged duration dependence; suppose the good job offer arrival rate would fall with unemployment duration in the control state. The idea is that the longer the individual stays unemployed, the lower the probability of receiving a good job offer. Such a phenomenon could arise from e.g. a 
stigma effect, if longer unemployment spells are perceived as a bad signal on the unemployed worker's ability. The treatment entails e.g. some activation programmes and JSA which enables the individual to overcome these detrimental impacts of long-term unemployment. The treatment then implies both faster job finding and a larger fraction of good jobs found. Hence, the treatment in this case implies that the negative duration dependence in the control state leads to lagged duration dependence in the sense that longer unemployment duration is associated with shorter jobs on average, while this is not the case in the treatment state.

Hence, if we observe an effect of the treatment on subsequent employment duration, it can be due to a 'direct' effect affecting the quality of jobs found via the search technology, but it may also be induced by stigma leading to a negative duration dependence. In our empirical specification, we decompose the effect into a direct and an indirect effect along these dimensions.

This distinction is important for the formulation of policy, since the policy implications of the two different causes differ; if (prevention of stigma and) negative duration dependence is the cause, then treatment should occur quickly in order to avoid a fall in transition rates to good jobs, while if the effect goes via a permanent positive effect on the transition rate to good jobs, then it becomes more important to ensure the quality of the treatment in order to obtain as large an effect as possible.

\section{Data}

\subsection{Description}

The data used for this study come from the administrative databases used by the case workers to register their dealings with the unemployed workers, from the central register on the labour market (CRAM) that registers UI benefit payments, and various other administrative registers. All data are collected by The National Labour Market Board and made available to the research community.

The data contain weekly information on the type of transfer received and the activities undertaken in each week (meetings, programmes, etc.) for each worker. Individuals are followed for 201 weeks from the week they enter the unemployment spell that triggered their participation in the experiment. We can thus retrieve the labour market history, i.e. the transitions between unemployment, self-sufficiency and inactivity over almost 4 years. We use the information on income transfer to construct unemployment, inactivity and selfsufficiency spells. An unemployment or inactivity spell is considered to have ended when the individual has not received UI benefits or some related benefit for more than four consecutive weeks.

Note that, regarding state occupancy, we only know whether the individual receives public transfers and if so, the type of transfer; this allows us to distinguish between unemployment (one type of transfer), inactivity (all other 
types of transfer), and self-sufficiency. However, we have no detailed information allowing us to determine if what we call 'self-sufficiency' is the same as employment. However, in the following, we will often refer to 'self-sufficiency' as 'employment', and the justification for such an assumption is as follows: First of all, the individuals in the experiments are all UI benefit recipients, that is, they are eligible for (and receiving) unemployment insurance for up to 4 years. Hence, there is no reason for leaving unemployment for a 'no income' state. Moreover, we conducted an exploratory analysis on data from the same source but from a more recent period when employment information is available. ${ }^{5}$ This analysis reveals that self-sufficiency spells correspond to employment spells in more than $95 \%$ of the cases. The implication of not having precise employment information is that we do not observe job-to-job transitions or wages, hence we evaluate the impact of treatment on employment (but not job) duration.

In addition to the information used to construct spells, the data contain some further information that can be used to construct control variables: gender, age at the time of registration, ethnicity (native Dane, being an immigrant or descendant originating in a Western country, or being an immigrant or descendant originating in a Non-Western country), UI fund (a proxy for educational attainment), and the fraction of time spent on public income transfer the 52 weeks immediately before becoming unemployed, 53-104 weeks before becoming unemployed, and 105-156 weeks before unemployment.

\subsection{Sample selection}

The total inflow to open unemployment in the period between week 43 of 2005 and week 8 of 2006 was 5180 individuals. Some of these were removed from the sample subsequently for various reasons (see Rosholm [2008] for the details of the data cleaning), among which incorrect assignment to treatment and control groups, death or emigration during the observation period and non-receipt of any UI benefits during the first six weeks of their unemployment spell. The resulting sample has 4485 individuals, and this is the sample which we shall analyze in the following.

Table 5 in the Appendix shows the composition of the sample by region and treatment status. Control variables are no remarkable different between treatments and controls, although there are minor regional differences. Thus, the sample selection process has not invalidated the experimental nature of the data.

\subsection{Descriptive analysis}

From a controlled experiment, one can measure the intention-to-treat effect by comparing labour market outcomes for the treatment and the control groups. Figures 1 and 2 plot the evolution of the differences between control and treatment groups in employment rates. Differences are calculated separately for each

\footnotetext{
${ }^{5}$ Data on employment are available starting from 2008.
} 
region and by gender. A positive value means that the employment rate is larger for the treatment group. The first 30 weeks in the graph correspond to the intended duration of the experiment. Over this first period, employment rates are higher in the treatment group than in the control group. The difference tends to become negative over time for women in Storstrøm county and close to zero for men in Storstrøm county, while it remains positive for both men and women in Southern Jutland county, suggesting that the longer-term effects may be different for men and women and between the two counties.

Figure 1: Differences in employment rates between treated and untreated women

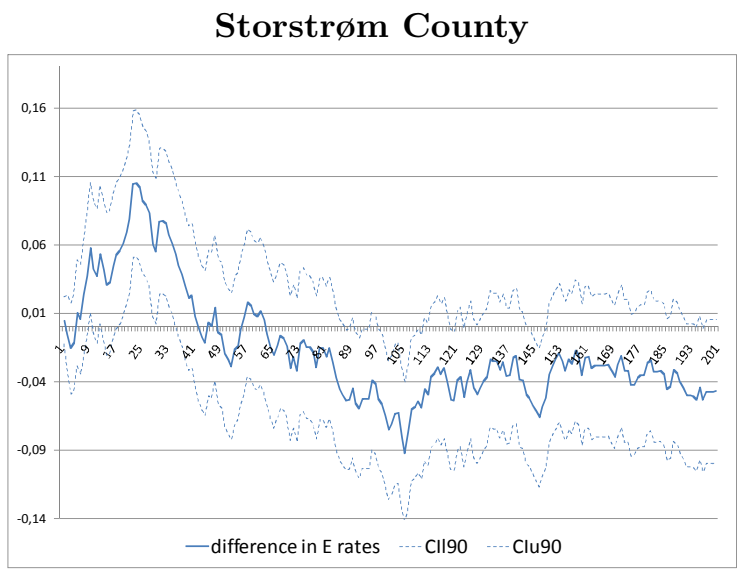

Southern Jutland County

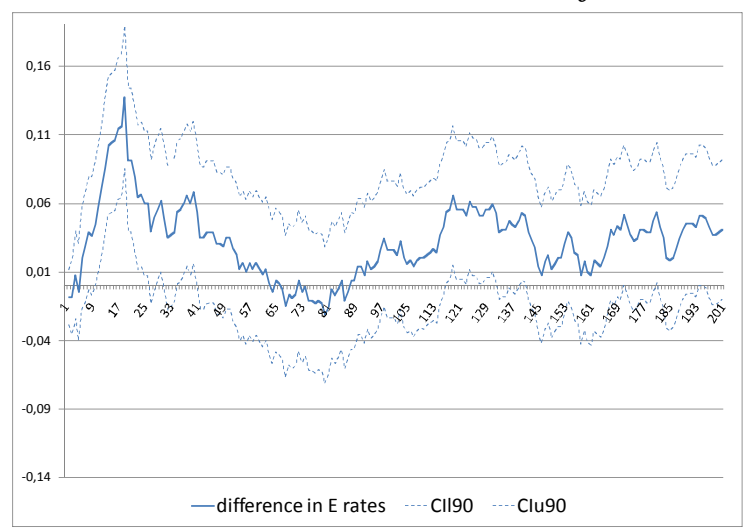

Figure 2: Differences in employment rates between treated and untreated men

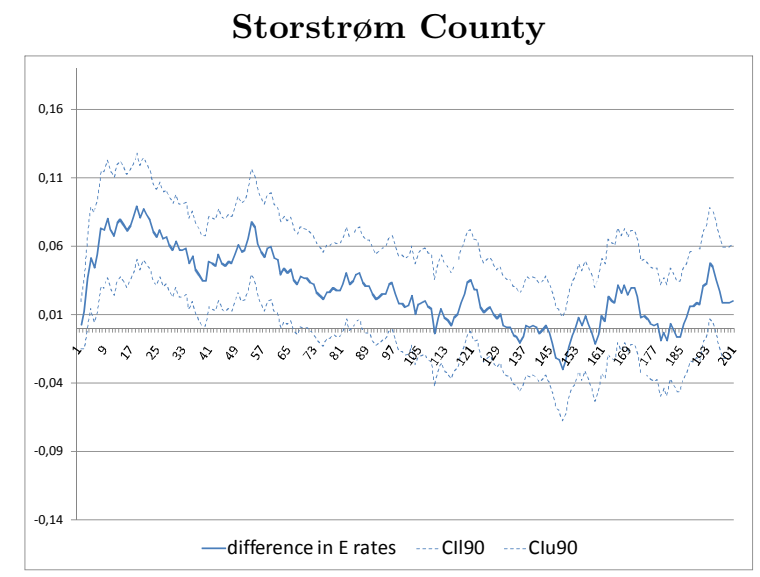

Southern Jutland County

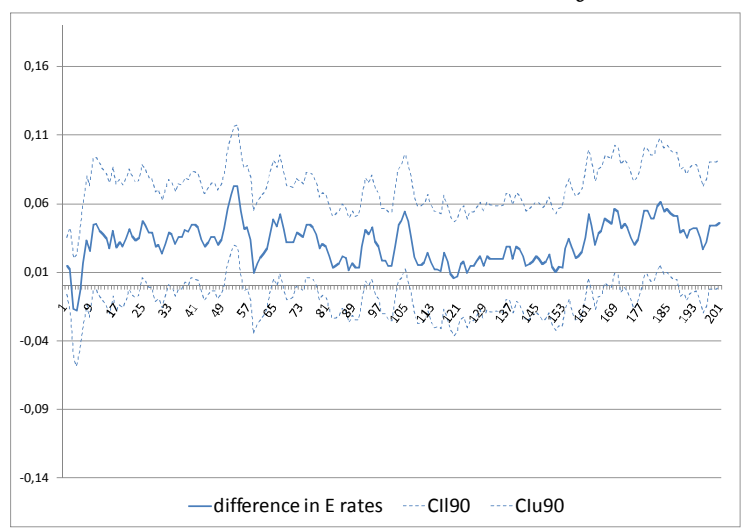

The following analysis focuses on the unemployment spell triggering participation in the experiment and the first employment spell ensuing participation in the experiment. Table 1 shows simple statistics to give a first idea of the correlation between assignment to intensive early treatment and the ensuing labour market history. In both counties, the average duration of unemployment 
is 2-7 weeks shorter in the treatment than in the control group, depending on the gender and the county. This runs along with previous results according to which early intensive treatment has a positive impact on exit rates. The difference is significant at $1 \%$ for women in the Southern Jutland county and for men in Storstrøm county. Surprisingly, even if the difference is insignificant, for women a larger part of unemployment spells end in withdrawal from the labour force and a smaller share exit to employment in the treatment than in the control group.

Table 1: Description of labour market outcomes

\begin{tabular}{|c|c|c|c|c|c|c|}
\hline & \multicolumn{6}{|c|}{ Women } \\
\hline & \multicolumn{3}{|c|}{ Storstrøm County } & \multicolumn{3}{|c|}{ Southern Jutland County } \\
\hline & Control & Treated & $\mathrm{z}$ or $\mathrm{t}$ test & Control & Treated & $\mathrm{z}$ or $\mathrm{t}$ test \\
\hline & \multicolumn{6}{|c|}{ first unemployment spell } \\
\hline $\begin{array}{l}\text { mean duration } \\
\text { exit to }(\%)\end{array}$ & 23.69 & 21.08 & -1.6 & 27.44 & 20.67 & $-3.86^{* * *}$ \\
\hline inactivity & 16.87 & 17.23 & 0.15 & 17.05 & 20.08 & 1.21 \\
\hline \multirow[t]{2}{*}{ employment } & 83.13 & 82.54 & -0.24 & 82.33 & 79.71 & -1.04 \\
\hline & \multicolumn{6}{|c|}{ employment spell ensuing the experimental spell } \\
\hline $\begin{array}{l}\text { mean duration } \\
\text { exit to }(\%)\end{array}$ & 78.47 & 80.21 & 0.33 & 79.14 & 78.29 & -0.17 \\
\hline inactivity & 29.21 & 27.75 & -0.52 & 31.57 & 35.32 & 1.31 \\
\hline unemployment & 44.55 & 45.60 & 0.33 & 41.16 & 40.78 & -0.12 \\
\hline \multirow[t]{4}{*}{$\%$ censored } & 26.24 & 26.65 & 0.15 & 27.27 & 23.90 & -1.29 \\
\hline & \multicolumn{6}{|c|}{ Men } \\
\hline & \multicolumn{3}{|c|}{ Storstrøm County } & \multicolumn{3}{|c|}{ Southern Jutland County } \\
\hline & Control & Treated & $\mathrm{z}$ or $\mathrm{t}$ test & Control & Treated & $\mathrm{z}$ or $\mathrm{t}$ test \\
\hline & \multicolumn{6}{|c|}{ first unemployment spell } \\
\hline $\begin{array}{l}\text { mean duration } \\
\text { exit to }(\%)\end{array}$ & 15.84 & 11.99 & $-4.19^{* * *}$ & 16.26 & 14.88 & -1.14 \\
\hline inactivity & 7.60 & 7.30 & -0.22 & 7.47 & 7.22 & -0.16 \\
\hline \multirow[t]{2}{*}{ employment } & 92.40 & 92.70 & 0.22 & 92.53 & 92.61 & 0.05 \\
\hline & \multicolumn{6}{|c|}{ employment spell ensuing the experimental spell } \\
\hline $\begin{array}{l}\text { mean duration } \\
\text { exit to }(\%)\end{array}$ & 97.34 & 103.09 & 1.45 & 93.60 & 101.49 & $1.76 *$ \\
\hline inactivity & 22.72 & 22.88 & 0.07 & 25.33 & 25.10 & -0.09 \\
\hline unemployment & 48.88 & 46.51 & -0.91 & 47.47 & 44.11 & -1.15 \\
\hline$\%$ censored & 28.40 & 30.61 & 0.94 & 27.20 & 30.80 & 1.37 \\
\hline
\end{tabular}

Note: $*$ indicates statistical significance at the $10 \%$ level, ${ }^{* *}$ at the $5 \%$ level, and ${ }^{* * *}$ at the $1 \%$ level.

A new result is that among those who exit unemployment for employment (about $90 \%$ of men and $80 \%$ of women), employment stability is higher for the treated than for the untreated (here we use the terms treated vs untreated to underline the fact that we are no longer dealing with random samples), except for women in the Southern Jutland county. The differences are much larger for men than for women: in comparison with the untreated, the treated men stay 
employed on average 5 additional weeks in Storstrøm county and 8 additional weeks in Southern Jutland county. Only the latter difference is statistically significant at $10 \%$. For women, there are no significant differences between treated and untreated.

A comparison between counties reveals an interesting feature. In Storstrøm county, agencies focused more on the monitoring component of the treatment, while in the Southern Jutland county, the focus was more put on the counseling part. This is known from interviews with job centre officials, and it may explain some of the differences observed between the two counties. Specifically, the observation that the difference in unemployment durations between treatments and controls is larger in Storstrøm county than in Southern Jutland county, but at the same time, the difference in reemployment durations between treated and controls is smallest in Storstrøm county, runs along well with the argument developed earlier according to which earlier exits due to compulsion and monitoring may be damaging for the stability of reemployment spells.

Kaplan-Meier estimates (Figure 5 in the Appendix) reveal that treated men tend to stay employed longer than untreated men, while no significant difference is found for women.

To obtain a first idea on whether these differences in employment duration are only due to the large impact of the treatment on exit rates from unemployment or not (the indirect vs the direct effect), Table 2 shows how the treatment indicator and the lagged duration of unemployment affect the hazard rate from employment back into unemployment. Selection to employment is not modeled, the duration of the previous unemployment spell is taken taken to be exogenous, no other explanatory variables are included, and the baseline hazard is assumed piecewise constant.

Table 2: Just subsequent employment spell

\begin{tabular}{lcl}
\hline \hline \multicolumn{3}{c}{ Women } \\
\hline Treated & 0.013 & -0.021 \\
& $(0.059)$ & $(0.060)$ \\
lagged U duration & & $0.003 * * *$ \\
& \multicolumn{2}{c}{ Men } \\
\hline \hline & \multicolumn{2}{c}{ M.001) } \\
\hline Treated & $-0.097^{* * *}$ & -0.077 \\
lagged U duration & $(0.049)$ & $(0.049)$ \\
& & $0.004 * * *$ \\
& & $(0.001)$ \\
\hline \hline
\end{tabular}

PH models.

Sample: 2401 men and 1549 women who exit the experiment to enter employment.

Unemployment duration in weeks.

Note: $* * *$ indicates statistical significance at the $1 \%$ level.

For men, the treated have a $10 \%$ lower exit rate from employment than 
the untreated, while there is no difference between treated and untreated for women. Controlling for the time spent previously in unemployment reduces the size of the coefficient associated with treatment for men, where longer past unemployment duration is associated with lower employment duration. For women, the opposite is the case, suggesting more of a mover-stayer typology among the women (those who stay long in unemployment also tend to stay employed for longer). This might reflect that women who stay unemployed for long tend to find jobs more often in the public sector (where jobs last longer) This reveals the potential importance of the two types of effects developed in the theoretical framework, the direct effect appearing to be more important than the indirect effect (for men).

To conclude this section, the preliminary descriptive analyses reveal that the men in the treatment group have higher employment rates than men in the control group, and that on average treated male have significant longer postunemployment employment duration than untreated men, while there appears to be no difference for women. This may be due to an indirect or a direct effect, but it may also be due to selection with respect to who finds employment. For inference, we need to conduct a proper statistical duration analysis, correcting for selection into employment.

\section{Evaluation method}

\subsection{Randomization and dynamic selection bias}

Even if we use data from an experiment, the estimation of the treatment effects on transition rates is not straightforward; one cannot simply compare the transition rates of the treated and untreated because of dynamic selection (see Abbring and van den Berg [2005] for a detailed description of the problem). Starting from week 2, those in the treatment group are aware of the experiment and this might affect their behaviour. In this sense, starting from week 2 , the assumption of independence between the treatment and the unobserved characteristics is no longer valid. This leads to a bias in the estimated treatment effects on subsequent transition rates in and out of unemployment, if it is not accounted for.

For simplicity, consider a single-state single-spell duration framework. We denote $\theta(t \mid X, V, Z)$ the conditional exit rate with $X$ the observed heterogeneity, $V$ the unobserved component and $Z$ an indicator taking value 1 if the individual is assigned to the treatment group and 0 otherwise. In our experiment, the treatment and control groups have the same information set at duration times 0 and 1 , since the information letter is sent after 1 week of unemployment. Randomization thus implies that $Z$ is independent from $X, V$ at time $t=0$ and $t=1$. Formally,

$$
\begin{aligned}
& \theta(0 \mid X, Z=0) \quad \theta(0 \mid X, Z=1) \\
& \theta(1 \mid X, Z=0) \quad=\theta(1 \mid X, Z=1)
\end{aligned}
$$


In general, however, this equality does not hold for values of $t$ larger than 1 , since in the second week of unemployment individuals in the treatment group are provided with information about the new labour market policy regime (and hence the treatment starts), and that information may immediately affect their behaviour. The value of the observed hazard rate at time $t \geq 2$ is equal to

$$
\theta(t \mid X, Z)=E_{V}[\theta(t \mid X, Z, V) \mid T \geq t]
$$

The expression depends on the distribution of $V$ conditional on survival in unemployment at least until $t$. This distribution can be derived by a straightforward application of Bayes' rule :

$$
f_{V}(V \mid Z, T \geq t)=\frac{\bar{F}(t \mid Z, V) \cdot g_{V}(V)}{\int \bar{F}(t \mid Z, V) \cdot d G_{V}(V)}
$$

It is clear that as long as the distribution of $T$ does not depend on $Z$, there is no problem, but when information about the experiment arrives (in the form of a letter) to the unemployed workers, the experiment starts affecting the hazard rates of individuals in the treatment and control groups differently, and therefore the conditional distribution $\bar{F}(t \mid V)$ depends on $Z$. This phenomenon is known in the literature as 'dynamic sample selection', and it implies that, although the distribution of unobservables is identical in the treatment and control groups at the time of randomization, $t=0$, once the experiment starts affecting the exit rates from unemployment, the distribution of unobservables among the survivors in unemployment will start to differ between the treatment and control groups.

In terms of treatment effect, the measure $\frac{\theta(t \mid Z=1)}{\theta(t \mid Z=0)}$, which captures the treatment effect when there is no dynamic selection, is no longer relevant here. Indeed,

$$
\frac{\theta(t \mid Z=1)}{\theta(t \mid Z=0)}=\frac{E(\theta(t \mid Z=1, V) \mid T \geq t, Z=1)}{E(\theta(t \mid Z=0, V) \mid T \geq t, Z=0)}
$$

so that it captures both the treatment effect and the selection. Hence, an identification strategy must be able to account for dynamic selection bias. This is exactly the strength of the duration model framework, where the hazard rates - the selection process out of the state of interest - are explicitly modeled. If one wants to proceed non-parametrically, Abbring and van den Berg [2005] show that with the assumption of proportional hazards and an additional assumption of monotonicity of the effect of treatment on the relative hazard - e.g. the treatment effect is positive (negative) at all durations - the difference in the empirical hazard rates constitutes a lower (upper) bound on the true treatment effect.

When we extend the problem to post-unemployment outcomes, we need to deal with spurious correlations arising from a non-random selection into employment. To do so, we allow the transition-specific unobserved terms to be correlated. The random effects assumption, according to which treatment and unobserved explanatory variables are independent in the inflow to unemployment, is satisfied by construction due to the randomization of $Z$. 


\subsection{Identification of direct and indirect effects}

The empirical model we construct is a reduced-form model in which hazard rates are allowed to vary over time and across observed and unobserved individual characteristics. To account for the fact that treatment may affect unemployment duration and that unemployment duration may affect post-unemployment outcomes unconditional on treatment, we jointly estimate transition rates from unemployment to employment and transition rates from subsequent employment. 6

To highlight the mechanisms at play, we evaluate the intention-to-treat effect, i.e. the effect of being assigned to the treatment group, on the transition rate from unemployment to employment and on the subsequent transition rate from employment back into unemployment. We compare the effects depending on whether we account for lagged duration dependence or not.

We use a factor-loading specification for the unobserved heterogeneity distribution. We do not impose a priori a fixed number of mass points in the distribution of the unobserved components, but use the Akaike Information Criterion to decide the number of mass points. The baseline hazard is piecewise constant. We control for various explanatory variables and estimate the models separately for men and women.

We focus on the two first spells, i.e. the unemployment spell that triggers entry in the experiment, and the following employment spell if there is one. We assume that the transition rate from unemployment to employment, denoted by $\theta_{u e}\left(t \mid X_{u e}, V_{u e}, Z\right)$ takes the mixed proportional hazard specification:

$$
\theta_{u e}\left(t \mid X_{u e}, V_{u e}, Z\right)=\lambda_{u e}(t) \exp \left(X_{u e}^{\prime} \beta_{u e}\right) \exp \left(\delta_{u e}(t) Z\right) \exp \left(V_{u e}\right)
$$

Here, treatment causes a shift upward or downward in hazard rates. We do allow for time-varying treatment effects; $\delta_{u e}(t)$, in the sense that we allow the treatment effect to differ during the experimental period (the first 30 weeks after entry into the experiment) and after it. Formally, this means that we take $\delta_{u e}\left(t \mid X_{u e}\right)=\delta_{u e}^{1} 1(t \leq 30)+\delta_{u e}^{1} 1(t>30)$.

In the subsequent employment spell, if there is one, having received the treatment results in a constant upward or downward shift of the respective hazard. The transition rate from employment back into unemployment is specified as:

$$
\theta_{\text {eu }}\left(t \mid X_{\text {eu }}, V_{\text {eu }}, Z\right)=\lambda_{\text {eu }}(t) \exp \left(X_{\text {eu }}^{\prime} \beta_{\text {eu }}+f\left(t_{u}\right)\right) \exp \left(\delta_{\text {eu }} Z\right) \exp \left(V_{\text {eu }}\right)
$$

with $f\left(t_{u}\right)$ a function of past unemployment duration. We use a piecewise constant function for lagged duration rather than the linear function assumed in the descriptive section. The results are not sensitive to this assumption. The

\footnotetext{
${ }^{6}$ In supplementary estimations, we also model transitions to non participation. Results showed no significant impacts of treatment status on participation, and other parameters are not sensitive to the inclusion or exclusion of this additional state. Results are displayed in Tables 8 and 9 in the Appendix.
} 
parameters associated with $f\left(t_{u}\right)$ capture lagged duration dependence and a potential indirect effect of treatment, while $\delta_{e u}$ captures the direct treatment effect on the $e u$ hazard rate. The lagged duration dependence and the direct treatment effect are non-parametrically identified in a mixed proportional hazard model (see Horny and Picchio [2009] for the detailed identification proof of such a competing risks model with lagged duration dependence). With such a specification, we assume that treatment has a constant effect on the transition rate from employment to unemployment, and that the functional form of lagged unemployment duration dependence is independent of the treatment status. As the treatment parameter does not depend on the elapsed duration in unemployment, we estimate the intention-to-treat effect.

\section{Results}

Tables 3 and 4 summarize the treatment effects estimated with different specifications (Tables 6 and 7 in the Appendix show the complete set of results in the preferred specification). The upper part displays the estimated parameter associated with the ITT status in the hazard rate from the unemployment spell to reemployment, while the bottom part shows the impact of the ITT status on the exit rate from the subsequent employment spell. We compare the results obtained depending on whether we control for lagged duration dependence or not and whether we include unobserved heterogeneity or not.

For men (Table 3), being assigned to the treatment group significantly increases the exit rate from unemployment to employment, while the experiment is ongoing. Afterwards, there is still a positive treatment effect, but it is not statistically significant. This result is very robust across the different specifications. With respect to the transition rate from employment back into unemployment, we find that treatment significantly reduces unemployment recurrence for men. This can be observed from the second and the fourth columns of results. Again, this result does not change much, when unobserved heterogeneity is introduced. The implication is that treatment causes more than a $9 \%$ reduction in the transition rate from employment to unemployment, implying that treated individuals find much more stable employment than untreated ones. This is consistent with the idea developed in the search model that treatment improves the search technology for good jobs. Moreover, the idea of a threat effect leading to bad jobs does not find any support, on the contrary.

The question remains, however, whether the treatment effect really arises due to an improvement in the search technology or due to an indirect effect stemming from the stigma associated with long-term unemployment. The results in the first and third columns shed some light on this. Controlling for lagged duration dependence, and hence for the indirect effect, we find that the direct effect becomes slightly smaller in numerical terms, such that the direct effect shrinks to slightly below an $8 \%$ reduction in the transition rate out of unemployment. Hence, the direct effect accounts for more than $80 \%$ of the total effect ( $83 \%$ to be precise). 
Table 3: Parameters of interest in the hazards - men

\begin{tabular}{|c|c|c|c|c|}
\hline & \multicolumn{4}{|c|}{ From Non Employment to Employment } \\
\hline \multirow[t]{2}{*}{$\delta * 1(t<30)$} & $0.170^{* * *}$ & $0.170^{* * *}$ & $0.177^{* * *}$ & $0.178^{* * *}$ \\
\hline & $(0.042)$ & $(0.042)$ & $(0.045)$ & $(0.045)$ \\
\hline \multirow[t]{3}{*}{$\delta * 1(t>30)$} & 0.082 & 0.081 & 0.231 & 0.225 \\
\hline & $(0.137)$ & $(0.137)$ & $(0.194)$ & $(0.197)$ \\
\hline & \multicolumn{4}{|c|}{ From Employment to Non Employment } \\
\hline \multirow[t]{2}{*}{$\delta$} & -0.076 & $-0.094 * * *$ & $-0.081 * *$ & $-0.097 * * *$ \\
\hline & $(0.048)$ & $(0.047)$ & $(0.049)$ & $(0.048)$ \\
\hline \multicolumn{5}{|c|}{ lagged unemployment duration (weeks. ref: below 6) } \\
\hline \multirow[t]{2}{*}{$6-8$} & $0.134 * *$ & & $0.196 * * *$ & \\
\hline & $(0.076)$ & & $(0.080)$ & \\
\hline \multirow[t]{2}{*}{$9-16$} & $0.269 * * *$ & & $0.346 * * *$ & \\
\hline & $(0.062)$ & & $(0.068)$ & \\
\hline \multirow[t]{2}{*}{$17-28$} & $0.400 * * *$ & & $0.474 * * *$ & \\
\hline & $(0.075)$ & & $(0.082)$ & \\
\hline \multirow[t]{2}{*}{$29-52$} & $0.444 * * *$ & & $0.473 * * *$ & \\
\hline & $(0.106)$ & & $(0.117)$ & \\
\hline \multirow[t]{2}{*}{52 or more } & $0.423 * * *$ & & $0.341 * * *$ & \\
\hline & $(0.137)$ & & $(0.171)$ & \\
\hline obs. hetero. & YES & YES & YES & YES \\
\hline unobs. hetero. & $\mathrm{NO}$ & $\mathrm{NO}$ & YES & YES \\
\hline lagged dur. dep. & YES & $\mathrm{NO}$ & YES & $\mathrm{NO}$ \\
\hline
\end{tabular}


For women, the estimates of main interest are displayed in Table 4. Women in the treatment group have significantly higher transition rates from unemployment to employment, while the experiment is ongoing. Afterwards it becomes negative but insignificant. We do not find any effect on the transition rate from employment back into unemployment for women. Neither do we, in this specification, find any difference in the size of the treatment effect whether we account for lagged duration dependence or not.

Table 4: Parameters of interest in the hazards - women

\begin{tabular}{|c|c|c|c|c|}
\hline & \multicolumn{4}{|c|}{ From Non Employment to Employment } \\
\hline \multirow[t]{2}{*}{$\delta * 1(t<30)$} & $0.160^{* * *}$ & $0.160 * * *$ & $0.194^{* * *}$ & $0.180^{* * *}$ \\
\hline & $(0.055)$ & $(0.055)$ & $(0.061)$ & $(0.061)$ \\
\hline \multirow[t]{3}{*}{$\delta * 1(t>30)$} & -0.114 & -0.114 & 0.015 & -0.046 \\
\hline & $(0.098)$ & $(0.098)$ & $(0.146)$ & $(0.162)$ \\
\hline & \multicolumn{4}{|c|}{ From Employment to Non Employment } \\
\hline \multirow[t]{2}{*}{$\delta$} & -0.019 & -0.013 & -0.029 & -0.013 \\
\hline & $(0.055)$ & $(0.055)$ & $(0.056)$ & $(0.055)$ \\
\hline \multicolumn{5}{|c|}{ lagged unemployment duration $($ weeks,ref: $<6$ ) } \\
\hline \multirow[t]{2}{*}{$6 \_8$} & -0.136 & & -0.145 & \\
\hline & $(0.109)$ & & $(0.109)$ & \\
\hline \multirow[t]{2}{*}{$9 \_16$} & 0.029 & & 0.015 & \\
\hline & $(0.086)$ & & $(0.081)$ & \\
\hline \multirow[t]{2}{*}{$17 \_28$} & 0.098 & & 0.070 & \\
\hline & $(0.086)$ & & $(0.088)$ & \\
\hline \multirow[t]{2}{*}{$29 \_52$} & -0.065 & & -0.122 & \\
\hline & $(0.104)$ & & $(0.110)$ & \\
\hline \multirow[t]{2}{*}{52} & $-0.174 *$ & & $-0.367 * * *$ & \\
\hline & $(0.101)$ & & $(0.144)$ & \\
\hline obs. hetero. & YES & YES & YES & YES \\
\hline unobs. hetero. & $\mathrm{NO}$ & $\mathrm{NO}$ & YES & YES \\
\hline lagged dur. dep. & YES & $\mathrm{NO}$ & YES & $\mathrm{NO}$ \\
\hline
\end{tabular}

MPH models, joint estimation on first unemployment and ensuing employment spells.

2 mass points for the distribution of unobserved heterogeneity. Standard errors in parentheses.

Note: * indicates statistical significance at the $10 \%$ level and *** at the $1 \%$ level.

Sample: 1891 women.

In terms of the theoretical framework, our results suggest that, for men, the direct effect is dominating, implying that treatment improves their search technology. Hence, not only do men in the treatment group find jobs faster than those in the control group, bot they are also able to stay employed. This suggests to us that the counseling element of meetings are more important than the monitoring element, and, moreover, that threat effects are less important than post-programme effects of participation in ALMPs. This goes against the 
suggestive results obtained by Rosholm [2008] as well as those of Graversen and van Ours [2009]. However, the first paper only studied the first unemployment spell and did not look at employment, while the second did look at employment but had a fairly short observation period.

For women, we find no effect on employment duration, suggesting that the search technology is improved in the sense of leading to faster job finding, but not in the sense of leading to more stable employment. However, we do not find evidence on the contrary, which would be caused by threat effects, either.

\section{Conclusion}

We study the long-term effects of an intensification of active labour market policies, consisting of intensive counseling and monitoring, early job search assistance, and early and compulsory activation programmes, using data from a randomized experiment implemented in two Danish counties in the winter of 2005-6. Specifically, we study the effects of the policy intensification on transition rates between non employment and employment and on the reemployment duration. The policy studied in this paper, shows remarkably large positive short run effects, corresponding to an increase in the transition rate into employment of about $20 \%$. We study whether the effect tends to disappear over time, or whether there are effects beyond the short run effects on transition rates out of unemployment. Descriptive analysis reveals that treated workers have greater average post-unemployment employment than untreated ones. To explain these differences, we distinguish between a direct and an indirect effect of intensive activation on post-unemployment outcome: we investigate whether treatment acts directly on the long-term through human capital accumulation and/or an improvement in the match process, or indirectly by its sole impact on unemployment durations. Hence, we estimate a joint model of unemployment and subsequent employment durations, allowing for lagged duration dependence. We find that participation in the experiment leads to a dramatic reduction in unemployment duration, a result also found by Graversen and van Ours (2008) and Rosholm (2008). Moreover, we find that, for men, participation in the experiment lengthens subsequent employment duration by almost 10 per cent, while we find no effect for women. Estimates show that for men, the direct effects accounts for $80 \%$ of the overall effect of being assigned to intensive treatment. The remaining 20 per cent of this positive effect comes from the fact that participation reduces unemployment duration, and short unemployment duration leads to longer employment duration. Our results thus suggest that earlier and especially more intensive counseling and job search assistance are beneficial in the short and longer run. The non significant effects found for women may come from the fact that women react differently to treatment than men and/or from the fact that they are more likely to be hired in the public sector where job duration is much more homogenous than in the private sector, where men are more represented. Without more detailed data on jobs we cannot however test for this hypothesis. This gender difference will be the object of our future 
research. 


\section{Reference}

Abbring J.H. and van den Berg G.J. [2005]: "Social experiments and instrumental variables with duration outcomes", Tinbergen Institute, Discussion Paper, No. 2005-47.

Addison J.T., Blackburn M.L. and McKinley L. [2000]: "The Effects of Unemployment Insurance on Postunemployment Earnings", Labour Economics, Vol. 7, pp. 21-53.

Addison J.T. and Portugal P. [2002]: "Job Search Method and Outcomes", Oxford Economic Papers, Vol. 54.

Arni P., Lalive R. and van Ours J.C. [2009]: "How Effective Are Unemployment Benefit Sanctions? Looking Beyond Unemployment Exit", IZA Discussion Paper, No. 4509

Behncke S., Frölich M. and Lechner M. [2010]: "Unemployed and their caseworkers: should they be friends or foes?", Journal Of The Royal Statistical Society Series A, Vol. 173, pp. 67-92.

Belzil C. [2001]: "Unemployment Insurance and Subsequent Job Duration: job matching vs. unobserved heterogeneity", Journal of Applied Econometrics, 16:5, pp. 619-636.

Black D.A., Smith J.A., Berger M.C. and Noel B.J. [2003]: "Is the threat of reemployment services more effective than the services themselves? Evidence from random assignment in the UI system", American Economic Review, Vol. 93, pp. 1313-1327.

Blasco S. [2010]: "Le non recours à un système d'assurance chômage avec politiques actives d'emploi", Economie et Prévision, No. 192, 2010/1, pp. 1-25.

Card D., Kluve J. and Weber A. [2010]: "Active Labour Market Policy Evaluations: A Meta-Analysis", The Economic Journal, Vol. 120, No. 548, pp. F452-F477.

Cockx B. and Dejemeppe M. [2007]: "Is the Notification of Monitoring a Threat to the Unemployed? A Regression Discontinuity Approach" IZA discussion paper 2854, June, Institute for the Study of Labor, Bonn

Crépon B., Gurgand M. and Dejemeppe M. [2005]: "Counseling the Unemployed: Does it Lower Unemployment Duration and Recurrence?", Centre d'Etudes de l'Emploi, Document de Travail, No. 40.

Crépon B., Ferracci M., Jolivet G. and van den Berg G.J. [2010]: "Analyzing the Anticipation of Treatments Using Data on Notifification Dates", IZA Discussion Paper No. 5265.

Dolton P. and O'Neil D. [2002]: “The Long-Run Effects of Unemployment Monitoring and Work-Search Programs: Experimental Evidence from the United Kingdom", Journal of Labor Economics, Vol. 20, No. 2, pt. 1, pp. 381-403. 
Ehrenberg R.G. and Oaxaca R.L. [1976]: "Unemployment Insurance, Duration of Unemployment and Subsequent Wage Gain", American Economic Review, 66:5, pp. 754-776.

Geerdsen L.P. [2006]: "Is There a Threat Effect of Labour Market Programs? A Study of ALMP in the Danish UI System" Economic Journal vol. 6 No.513, pp. 738-750.

Geerdsen L.P. and Holm A. [2007]: "Duration of UI Periods and the Perceived Threat Effect from Labour Market Programmes" Labour Economics vol. 14 No.3, pp. 639-652.

Graversen B.K. and van Ours J.C. [2008]: "Activating unemployed workers works; Experimental evidence from Denmark", Economics Letter, Vol. 100, pp. $308-310$

Graversen B.K. and van Ours J.C. [2009]: "How a Mandatory Activation Program Reduces Unemployment Durations; the Effects of Distance", Forthcoming in Labour Economics.

Hägglund, P. [2006]: "Are there pre-programme effects of Swedish active labour market policies? Evidence from three randomised experiments". IFAU Working Paper 2006:2.

Heckman J.J., Lalonde R. and Smith J. [1999]: "The Economics and Econometrics of ALMP", Handbook of Labor Economics, Vol. 3, North-Holland, Amsterdam.

Horny G. and Picchio M. [2009]: "Identification of Lagged Duration Dependence in Multiple Spells Competing Risks Models", IRES Discussion Paper, No. 2009001.

Klepinger D.H., Johnson T.R. and Joesh J.M. [2002]: "Effects of Unemployment Insurance Work-Search Requirements: The Maryland Experiment" Industrial and Labor Relations Review, vol. 56 No.1, pp. 3-22.

Kluve J. [2006]: "The effectiveness of European Active Labor Market Policy", IZA Discussion Paper, No. 2018.

Kluve J. [2010]: "The effectiveness of European active labor market programs", Labour Economics 17, pp. 904918.

Kluve J. and Schmidt C.M. [2002]: "Can Training and Employment Subsidies Combat European Unemployment?", Economic Policy, Vol. 35, pp. 411448.

Lalive R. [2007]: "Unemployment Benefits, Unemployment Duration, and Post-Unemployment Jobs: A Regression Discontinuity Approach", American Economic Review (Papers and Proceedings), Vol. 91, No. 2, pp. 108-112.

Lalive R., van Ours J.C. and Zweimüller J. [2005]: "The Effect of Benefit Sanctions on the Duration of Unemployment", Journal of the European Economic Association, Vol. 3, No. 6, pp. 1386-1417. 
Larsson L. [2003]: "Evaluation of Swedish Youth Labor Market Programs", The Journal of Human Resources, Vol. 38, No. 4, pp. 891-927.

Lechner M., Miquel R. and Wunsch C. [2010]: "Long-Run Effects of Public Sector Sponsored Training in West Germany", Journal of European Economic Association, forthcoming.

Lechner M. and Wiehler S. [2010]: "Kids or courses? Gender differences in the effects of active labour market policies", Journal of Population Economics, forthcoming.

Lechner M. and Wunsch C. [2006]: "Are the effects of training programmes in Germany sensitive to the choice and measurement of labour market outcomes?", Journal of Labour Market Research (ZAF), Vol. 39, pp. 347-364.

Munch J.R. and Skipper L. [2005]: "The Consequences of Active Labour Market Programme Participation in Denmark", mimeo.

Rosholm M. [2008]: "Experimental Evidence on the Nature of the Danish Employment Miracle", IZA Discussion Paper, No. 3620.

Rosholm M. and Svarer M. [2008]: "Estimating the Threat Effect of Active Labour Market Programmes", Scandinavian Journal of Economics, Vol. 110, No. 2, pp.385-401.

Sianesi B. [2008]: "Differential Effects of Active Labour Market Programs for the Unemployed", Labour Economics, Vol. 15, No. 3, pp. 370-399.

Svarer M. [2010]: "The effect of sanctions on the exit rate from unemployment: Evidence from Denmark", Economica, forthcoming.

Tatsiramos K. [2006]: "Unemployment Insurance in Europe: Unemployment Duration and Subsequent Employment Stability", IZA Discussion Paper, No. 2280 .

Van den Berg G.J. and van der Klaauw B. [2006]: "Counseling and Monitoring of Unemployed Workers: Theory and Evidence from a Controlled Social Experiment", International Economic Review, Vol. 47, pp. 895-936.

Van den Berg G.J. and Vikström J. [2009]: "Monitoring Job Offer Decisions, Punishments, Exit to Work, and Job Quality", IZA Discussion Paper, No. 4325.

Van Ours J.C. [2007]: "Compulsion in Active Labour Market Programmes", National Institute Economic Review, Vol. 202, pp. 67-78.

Van Ours J.C. and Vodopivec M. [2008]: "Does Reducing Unemployment Insurance Generosity Reduce Job Match Quality?", Journal of Public Economics, Vol. 92, No. 3-4, pp. 684-695. 


\section{Appendix}

Figure 3: Timing of the treatment

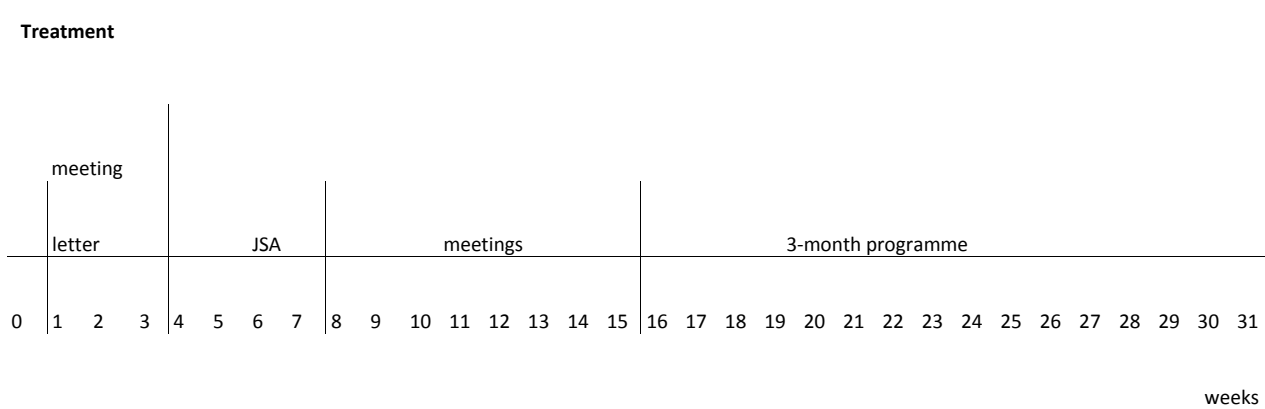

Control

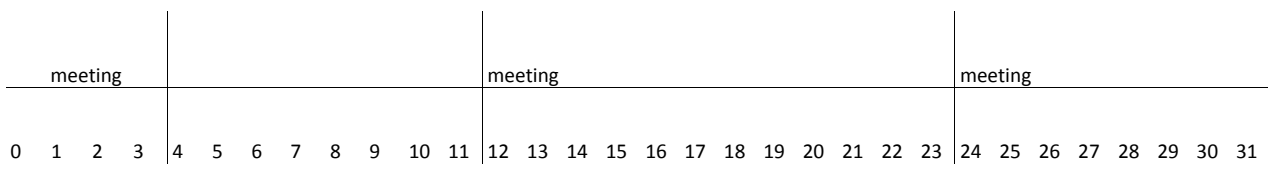

weeks 
Figure 4: Evolution of treatment intensity by group and region Meeting

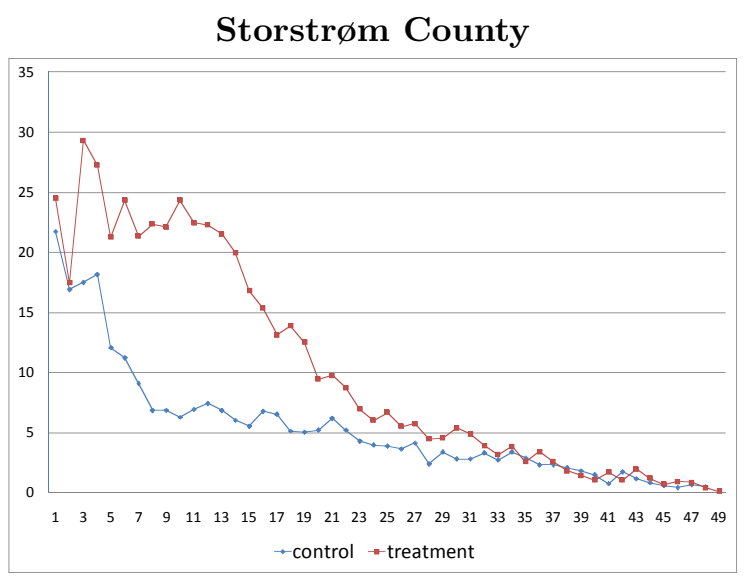

Southern Jutland County

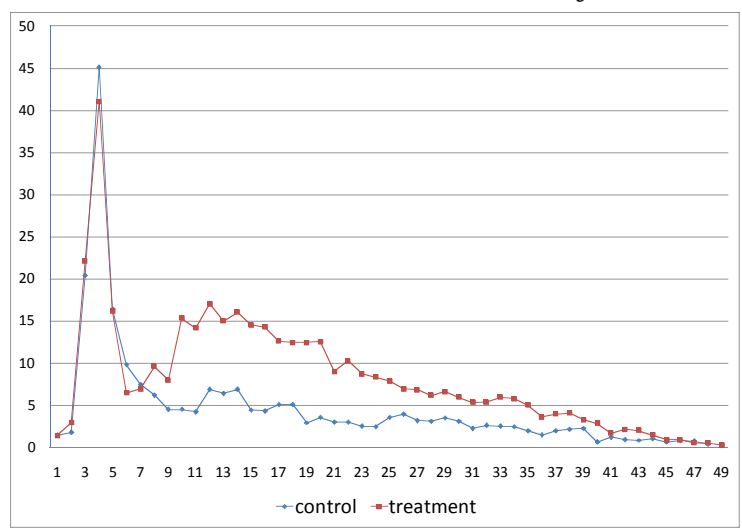

Activation programmes

Storstrøm County

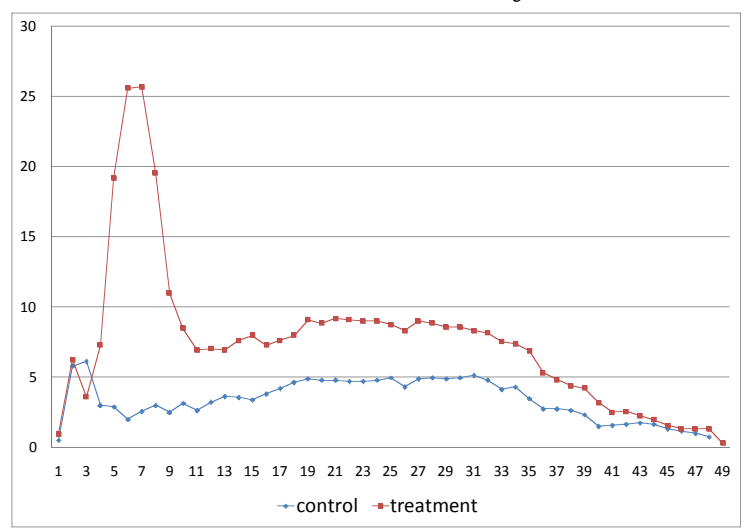

Southern Jutland County

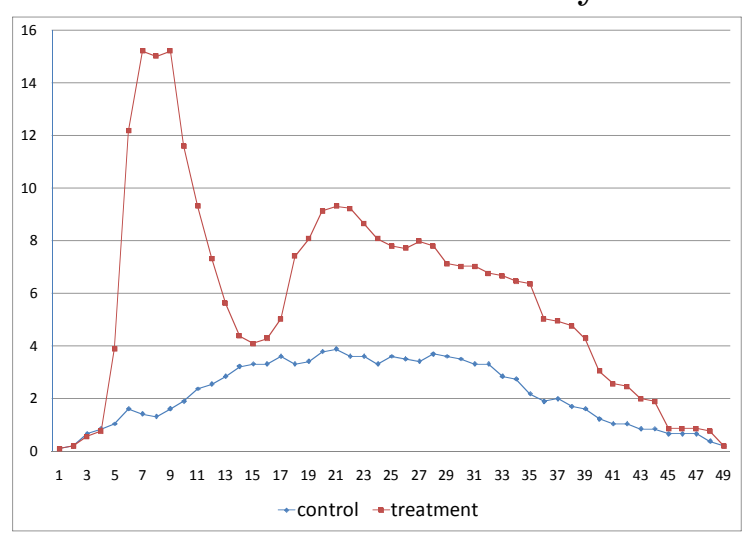


Table 5: Comparison in control variables between treatment and control groups

\begin{tabular}{|c|c|c|c|c|c|c|}
\hline & \multicolumn{3}{|c|}{ Storstrøm } & \multicolumn{3}{|c|}{ southern Jutland } \\
\hline & Control & Treatment & z-test & Control & Treatment & z-test \\
\hline $\mathbf{N}$ & 1210 & 1167 & & 1057 & 1051 & \\
\hline \multicolumn{7}{|l|}{ Age } \\
\hline less than 24 & 9.01 & 9.17 & 0.14 & 12.77 & 11.42 & -0.95 \\
\hline $25-29$ & 11.98 & 12.94 & 0.71 & 13.43 & 14.37 & 0.62 \\
\hline $30-39$ & 27.36 & 23.65 & -2.07 & 24.03 & 25.69 & 0.88 \\
\hline $40-49$ & 23.88 & 26.14 & 1.27 & 24.31 & 26.36 & 1.08 \\
\hline $50-59$ & 25.12 & 24.59 & -0.3 & 21.85 & 19.22 & -1.5 \\
\hline 60 and above & 2.64 & 3.51 & 1.23 & 3.6 & 2.95 & -0.83 \\
\hline \multicolumn{7}{|l|}{ UI fund (\%) } \\
\hline academics & 1.98 & 2.66 & 1.09 & 2.74 & 2.95 & 0.28 \\
\hline construction & 6.53 & 6.77 & 0.24 & 7.28 & 8.28 & 0.85 \\
\hline metal & 5.12 & 5.83 & 0.75 & 5.3 & 4.57 & -0.77 \\
\hline manufacturing & 41.82 & 42.42 & 0.3 & 35.86 & 34.06 & -0.86 \\
\hline technicians & 4.71 & 3.34 & -1.69 & 3.41 & 2.85 & -0.73 \\
\hline trade & 11.24 & 10.2 & -0.82 & 9.93 & 8.37 & -1.24 \\
\hline white collar & 9.42 & 10.03 & 0.5 & 10.31 & 9.9 & -0.32 \\
\hline others & 13.97 & 13.8 & -0.12 & 18.26 & 19.51 & 0.73 \\
\hline self-employed & 3.72 & 2.91 & -1.1 & 5.01 & 7.42 & 2.29 \\
\hline$\%$ male & 59.83 & 62.21 & 1.19 & 54.49 & 54.04 & -0.21 \\
\hline \multicolumn{7}{|l|}{ Ethnicity (\%) } \\
\hline Danish & 95.29 & 92.72 & -2.65 & 92.81 & 91.06 & -1.48 \\
\hline Western immigrant & 1.49 & 2.06 & 1.05 & 4.26 & 4.76 & 0.55 \\
\hline Non-western immigrant & 3.22 & 5.23 & 2.43 & 2.93 & 4.19 & 1.55 \\
\hline$\%$ married & 60.33 & 58.95 & -0.68 & 58.47 & 61.37 & 1.36 \\
\hline \multicolumn{7}{|c|}{ Past public income transfer rate } \\
\hline last year & 0.23 & 0.25 & 1.63 & 0.23 & 0.23 & -0.56 \\
\hline $1-2$ years ago & 0.28 & 0.31 & 2.1 & 0.29 & 0.29 & 0.16 \\
\hline $2-3$ years ago & 0.3 & 0.31 & 1.13 & 0.31 & 0.32 & 0.81 \\
\hline \multicolumn{7}{|l|}{ Starting week (\%) } \\
\hline 200 & 2.4 & 2.57 & 0.27 & 3.5 & 4.85 & 1.55 \\
\hline 201 & 9.26 & 9.6 & 0.28 & 11.16 & 10.09 & -0.8 \\
\hline 202 & 2.56 & 3 & 0.65 & 3.5 & 1.52 & -2.9 \\
\hline 203 & 2.64 & 3.17 & 0.76 & 2.84 & 3.33 & 0.65 \\
\hline 204 & 2.81 & 2.31 & -0.76 & 2.84 & 3.33 & 0.65 \\
\hline 205 & 8.02 & 5.83 & -2.1 & 9.08 & 9.32 & 0.19 \\
\hline 206 & 4.3 & 6.6 & 2.48 & 3.6 & 4.19 & 0.7 \\
\hline 207 & 3.64 & 4.63 & 1.21 & 2.93 & 4.95 & 2.38 \\
\hline 209 & 10.91 & 11.31 & 0.31 & 11.54 & 11.23 & -0.23 \\
\hline 210 & 16.53 & 15.51 & -0.68 & 15.42 & 15.41 & -0 \\
\hline 211 & 4.13 & 4.37 & 0.29 & 5.01 & 3.81 & -1.35 \\
\hline 212 & 3.06 & 4.2 & 1.49 & 3.5 & 3.33 & -0.22 \\
\hline 213 & 8.26 & 8.31 & 0.04 & 6.43 & 6.09 & -0.33 \\
\hline 214 & 11.24 & 9.94 & -1.03 & 9.74 & 9.61 & -0.1 \\
\hline 215 & 4.3 & 2.66 & -2.18 & 3.03 & 4.47 & 1.75 \\
\hline 216 & 2.73 & 3.77 & 1.44 & 3.12 & 1.33 & -2.78 \\
\hline 217 & 3.22 & 2.23 & -1.49 & 2.74 & 3.14 & 0.54 \\
\hline
\end{tabular}


Figure 5: Survival in employment by treatment status and gender women

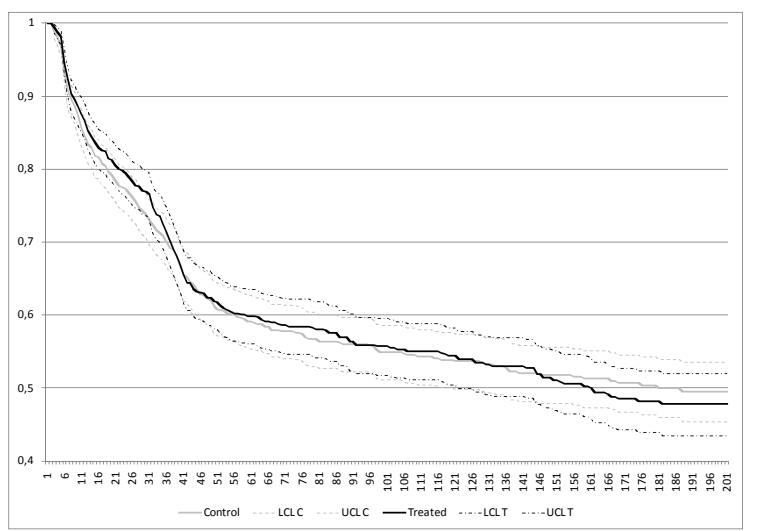

Kaplan-Meier estimate of the survival in employment (spell following the experiment). Sample: the 1549 women who exit the experiment to enter employment. homogeneity test: accepted.

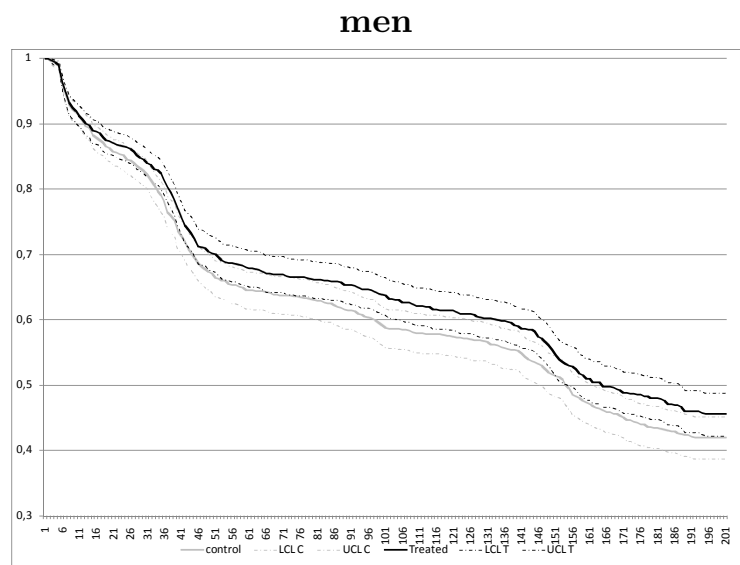

Kaplan-Meier estimate of the survival in employment (spell following the experiment). Sample: the 2401 men who exit the experiment to enter employment. homogeneity test : rejected at $5 \%$. 
Table 6: Estimation results for men not shown in the main table - preferred specification

\begin{tabular}{|c|c|c|c|c|}
\hline \multirow[b]{2}{*}{ Southern Jutland } & \multicolumn{2}{|c|}{$\begin{array}{c}\text { From Unemployment } \\
\text { to Employment }\end{array}$} & \multicolumn{2}{|c|}{$\begin{array}{l}\text { From Employment } \\
\text { to Non Employment }\end{array}$} \\
\hline & $-0.091 * *$ & $(0.046)$ & 0.002 & $(0.050)$ \\
\hline Married & $0.115 * *$ & $(0.049)$ & $-0.114 * *$ & $(0.053)$ \\
\hline \multicolumn{5}{|c|}{ Share of time on public income transfer } \\
\hline in previous year & $-0.485 * * *$ & $(0.123)$ & $0.587 * * *$ & $(0.125)$ \\
\hline 1-2 years ago & -0.079 & $(0.123)$ & 0.160 & $(0.132)$ \\
\hline $2-3$ years ago & $-0.322 * * *$ & $(0.100)$ & $0.334 * * *$ & $(0.110)$ \\
\hline \multicolumn{5}{|c|}{ UI fund (ref.: manufacturing) } \\
\hline construction & $0.851 * * *$ & $(0.125)$ & 0.112 & $(0.131)$ \\
\hline metal & 0.108 & $(0.129)$ & -0.037 & $(0.135)$ \\
\hline technicians & -0.120 & $(0.158)$ & $-0.381 * *$ & $(0.172)$ \\
\hline trade & $-0.318 *$ & $(0.169)$ & 0.263 & $(0.170)$ \\
\hline funk & -0.088 & $(0.163)$ & $-0.387 * *$ & $(0.181)$ \\
\hline academics & $-0.334 *$ & $(0.174)$ & $-0.695 * * *$ & $(0.205)$ \\
\hline self-employed & $-0.298 *$ & $(0.159)$ & $0.360 * *$ & $(0.155)$ \\
\hline other & $0.310^{* * *}$ & $(0.109)$ & 0.166 & $(0.109)$ \\
\hline \multicolumn{5}{|l|}{ Age (ref.: 30-39) } \\
\hline below 24 & $0.154 *$ & $(0.082)$ & 0.127 & $(0.094)$ \\
\hline $25-29$ & 0.061 & $(0.079)$ & 0.002 & $(0.091)$ \\
\hline $40-49$ & -0.051 & $(0.063)$ & 0.106 & $(0.072)$ \\
\hline above 50 & $-0.210^{* * *}$ & $(0.068)$ & $0.470 * * *$ & $(0.069)$ \\
\hline \multicolumn{5}{|c|}{ Nationality (ref.: Danish) } \\
\hline Western immigrant & -0.095 & $(0.135)$ & 0.192 & $(0.140)$ \\
\hline Non-western immigrant & $-0.491 * * *$ & $(0.132)$ & $0.448 * * *$ & $(0.138)$ \\
\hline
\end{tabular}

Week of entry in the experiment (ref.: weeks 1 or 2 )

$\begin{array}{lll}3-4 & -0.055 & (0.113) \\ 5-6 & -0.120 & (0.090) \\ 7-8 & -0.042 & (0.120) \\ 9-10 & 0.180^{* *} & (0.076) \\ 11-12 & 0.455^{* * *} & (0.099) \\ 13-14 & 0.490^{* * *} & (0.083) \\ 15-17 & 0.270^{* * *} & (0.100)\end{array}$

Baseline hazard (in weeks)

$\begin{array}{lllll}0-1 & -1.828 * * * & (0.332) & & \\ 1-2 \text { or } 0-2 & -1.215^{* * *} & (0.333) & -2.746 * * * & (0.309) \\ 3-4 & -1.019^{* * *} & (0.336) & -1.533^{* * *} & (0.292) \\ 5-8 & -1.013^{* * *} & (0.337) & -1.715^{* * *} & (0.301) \\ 9-16 & -0.924 * * * & (0.335) & -2.236 * * * & (0.299) \\ 17-30 & -0.866 * * * & (0.336) & -2.467 * * * & (0.294) \\ 31-52 & -1.446 * * * & (0.360) & -1.846^{* * *} & (0.286) \\ 52 \text { or more } & -1.956 * * * & (0.403) & -2.656 * * * & (0.283)\end{array}$

Unobserved heterogeneity

$\nu_{1}$

$\nu_{2}$

$\nu_{3}$

$P\left(\nu=\nu_{1}\right)$

$P\left(\nu=\nu_{2}\right)$
0

$-4.654 * * *$

$-1.704 * * *$

$-3.827 * * *$

$-3.097 * * *$
0

(0.529) $-1.406 * * *$

$(0.507)$

(0.258)

MPH models. Joint estimation on first unemployment and ensuing employment spells. Sample: 2594 men.

3 mass points for the distribution of unobserved heterogeneity. Standard errors in parentheses.

Note: $*$ indicates statistical significance at the $10 \%$ level, $* *$ at the $5 \%$ level, and $* * *$ at the $1 \%$ level. 
Table 7: Estimation results for women not shown in the main table - preferred specification

\begin{tabular}{|c|c|c|c|c|}
\hline \multirow[b]{2}{*}{ Southern Jutland } & \multicolumn{2}{|c|}{$\begin{array}{c}\text { From Unemployment } \\
\text { to Employment }\end{array}$} & \multicolumn{2}{|c|}{$\begin{array}{l}\text { From Employment } \\
\text { to Non Employment }\end{array}$} \\
\hline & -0.070 & $(0.061)$ & 0.025 & $(0.056)$ \\
\hline Married & 0.047 & $(0.068)$ & $-0.125^{* *}$ & $(0.062)$ \\
\hline \multicolumn{5}{|c|}{ Share of time on public income transfer } \\
\hline in previous year & $-0.445 * * *$ & $(0.108)$ & $0.471^{* * *}$ & $(0.102)$ \\
\hline $1-2$ years ago & -0.140 & $(0.124)$ & 0.077 & $(0.117)$ \\
\hline $2-3$ years ago & 0.047 & $(0.102)$ & 0.042 & $(0.097)$ \\
\hline \multicolumn{5}{|c|}{ UI fund (ref.: manufacturing) } \\
\hline construction & $0.426 * *$ & $(0.199)$ & -0.151 & $(0.185)$ \\
\hline metal & $-1.083 * *$ & $(0.532)$ & 0.446 & $(0.515)$ \\
\hline technicians & -0.286 & $(0.198)$ & $-0.397 *$ & $(0.212)$ \\
\hline trade & $-0.339 * * *$ & $(0.103)$ & -0.051 & $(0.097)$ \\
\hline funk & -0.053 & $(0.104)$ & $-0.222 * *$ & $(0.098)$ \\
\hline academics & $-0.341 *$ & $(0.188)$ & 0.017 & $(0.191)$ \\
\hline self-employed & $-0.629 * * *$ & $(0.186)$ & $0.290 *$ & $(0.153)$ \\
\hline other & $-0.247 * * *$ & $(0.092)$ & 0.108 & $(0.085)$ \\
\hline \multicolumn{5}{|l|}{ Age (ref.: 30-39) } \\
\hline below 24 & $0.233 *$ & $(0.123)$ & 0.021 & $(0.105)$ \\
\hline $25-29$ & -0.129 & $(0.095)$ & -0.003 & $(0.091)$ \\
\hline $40-49$ & 0.023 & $(0.080)$ & -0.075 & $(0.078)$ \\
\hline above 50 & $-0.299 * * *$ & $(0.098)$ & $0.308 * * *$ & $(0.082)$ \\
\hline \multicolumn{5}{|c|}{ Nationality (ref.: Danish) } \\
\hline Western immigrant & -0.200 & $(0.184)$ & -0.023 & $(0.165)$ \\
\hline Non-western immigrant & $-0.258 *$ & $(0.135)$ & 0.088 & $(0.132)$ \\
\hline
\end{tabular}

Week of entry into the experiment (ref.: weeks 1 or 2)

$\begin{array}{lll}3-4 & 0.152 & (0.134) \\ 5-6 & 0.109 & (0.100) \\ 7-8 & 0.327^{*} & (0.188) \\ 9-10 & 0.273^{* * *} & (0.089) \\ 11-12 & 0.325^{* *} & (0.145) \\ 13-14 & 0.069 & (0.099) \\ 15-17 & 0.362 * * * & (0.118)\end{array}$

Baseline hazard (in weeks)

$\begin{array}{lllll}0-1 & -3.192 * * * & (0.182) & & \\ 1-2 \text { or } 0-2 & -2.584 * * * & (0.162) & -4.190 * * * & (0.175) \\ 3-4 & -2.776 * * * & (0.153) & -3.232 * * * & (0.146) \\ 5-8 & -2.978 * * * & (0.148) & -3.823 * * * & (0.147) \\ 9-16 & -2.643 * * * & (0.144) & -4.250 * * * & (0.143) \\ 17-30 & -2.748 * * * & (0.157) & -4.577 * * * & (0.141) \\ 31-52 & -3.172 * * * & (0.186) & -4.427 * * * & (0.134) \\ 52 \text { or more } & -3.058 * * * & (0.206) & -5.316 * * * & (0.128)\end{array}$

Unobserved heterogeneity

\begin{tabular}{|c|c|c|c|c|}
\hline$\nu_{1}$ & 0 & & 0 & \\
\hline$\nu_{2}$ & $-2.019 * * *$ & $(0.247)$ & $0.695 * * *$ & $(0.273)$ \\
\hline$P\left(\nu=\nu_{1}\right)$ & $-1.962 * * *$ & $(0.278)$ & & \\
\hline
\end{tabular}


Table 8: Estimation results with 3 states - men

\begin{tabular}{|c|c|c|c|c|c|c|c|c|}
\hline & \multicolumn{4}{|c|}{ From Unemployment to } & \multicolumn{4}{|c|}{ From Employment to } \\
\hline & \multicolumn{2}{|c|}{ Employment } & \multicolumn{2}{|c|}{ Inactivity } & \multicolumn{2}{|c|}{ Unemployment } & \multicolumn{2}{|c|}{ Inactivity } \\
\hline \multicolumn{9}{|c|}{ Assignment to treatment group } \\
\hline$\delta * 1(t<30)$ & $0.175 * * *$ & $(0.047)$ & -0.307 & $(0.299)$ & & & & \\
\hline$\delta * 1(t>30)$ & $0.295 *$ & $(0.171)$ & 0.001 & $(0.318)$ & & & & \\
\hline$\delta$ & & & & & -0.090 & $(0.057)$ & 0.033 & $(0.201)$ \\
\hline Southern Jutland & $-0.082 *$ & $(0.048)$ & -0.210 & $(0.242)$ & -0.011 & $(0.058)$ & 0.272 & $(0.204)$ \\
\hline Married & $0.152 * * *$ & $(0.050)$ & $0.451 *$ & $(0.255)$ & -0.092 & $(0.061)$ & $0.525 * *$ & $(0.225)$ \\
\hline \multicolumn{9}{|c|}{ Share of time on public income transfer } \\
\hline in previous year & $-0.671 * * *$ & $(0.123)$ & $1.211 * * *$ & $(0.450)$ & $0.766 * * *$ & $(0.140)$ & -0.464 & $(0.567)$ \\
\hline $1-2$ years ago & -0.068 & $(0.125)$ & 0.372 & $(0.529)$ & $0.371 * * *$ & $(0.145)$ & -0.309 & $(0.542)$ \\
\hline $2-3$ years ago & $-0.316 * * *$ & $(0.103)$ & 0.257 & $(0.446)$ & $0.276 * *$ & $(0.124)$ & 0.616 & $(0.433)$ \\
\hline \multicolumn{9}{|c|}{ UI fund (ref.: manufacturing) } \\
\hline construction & $1.001 * * *$ & $(0.125)$ & -0.013 & $(0.600)$ & 0.075 & $(0.158)$ & 0.282 & $(0.508)$ \\
\hline metal & $0.280 * *$ & $(0.129)$ & 0.358 & $(0.509)$ & -0.120 & $(0.167)$ & 0.346 & $(0.504)$ \\
\hline technicians & -0.172 & $(0.152)$ & -0.235 & $(0.576)$ & -0.210 & $(0.204)$ & -1.085 & $(0.819)$ \\
\hline trade & $-0.329 * *$ & $(0.161)$ & -0.931 & $(0.722)$ & 0.204 & $(0.200)$ & 0.873 & $(0.553)$ \\
\hline funk & -0.089 & $(0.164)$ & 0.227 & $(0.581)$ & 0.127 & $(0.202)$ & 0.249 & $(0.603)$ \\
\hline academics & -0.179 & $(0.184)$ & 0.841 & $(0.658)$ & -0.086 & $(0.241)$ & -0.683 & $(0.827)$ \\
\hline self-employed & -0.230 & $(0.150)$ & 0.589 & $(0.527)$ & $0.435 * *$ & $(0.181)$ & $-1.363 *$ & $(0.828)$ \\
\hline other & $0.449 * * *$ & $(0.104)$ & -0.103 & $(0.436)$ & $0.285 * *$ & $(0.128)$ & 0.147 & $(0.423)$ \\
\hline \multicolumn{9}{|l|}{ Age (ref.: 30-39) } \\
\hline below 24 & $0.181 * * *$ & $(0.089)$ & $0.957 * *$ & $(0.435)$ & $0.229 *$ & $(0.115)$ & 0.381 & $(0.379)$ \\
\hline $25-29$ & 0.093 & $(0.083)$ & -0.382 & $(0.470)$ & 0.034 & $(0.105)$ & 0.361 & $(0.329)$ \\
\hline $40-49$ & -0.030 & $(0.067)$ & $-0.877 * *$ & $(0.410)$ & 0.236 *** & $(0.084)$ & $-0.787 * *$ & $(0.345)$ \\
\hline above 50 & $-0.272 * * *$ & $(0.069)$ & $0.534 *$ & $(0.317)$ & $0.539 * * *$ & $(0.082)$ & 0.341 & $(0.264)$ \\
\hline \multicolumn{9}{|c|}{ Nationality (ref.: Danish) } \\
\hline Western immigrant & 0.050 & $(0.142)$ & $-1.723 * *$ & $(0.809)$ & -0.015 & $(0.170)$ & $1.473^{* * *}$ & $(0.364)$ \\
\hline Non-western immigrant & $-0.572 * * *$ & $(0.133)$ & 0.513 & $(0.528)$ & $0.530 * * *$ & $(0.149)$ & -0.652 & $(0.769)$ \\
\hline \multicolumn{9}{|c|}{ Lagged unemployment duration (ref.: below 6 weeks) } \\
\hline $6-8$ & & & & & $0.231 * *$ & $(0.093)$ & 0.481 & $(0.309)$ \\
\hline $9-16$ & & & & & $0.339 * * *$ & $(0.079)$ & $0.502 *$ & $(0.282)$ \\
\hline $17-28$ & & & & & $0.580 * * *$ & $(0.091)$ & $0.644 *$ & $(0.338)$ \\
\hline $29-52$ & & & & & $0.469 * * *$ & $(0.139)$ & $0.912 *$ & $(0.506)$ \\
\hline 52 or more & & & & & 0.239 & $(0.233)$ & $3.112^{* * *}$ & $(0.513)$ \\
\hline \multicolumn{9}{|c|}{ Baseline hazard (in weeks) } \\
\hline $0-1$ & $-4.726 * * *$ & $(0.310)$ & $-7.101 * * *$ & $(1.161)$ & & & & \\
\hline $1-2$ or $0-2$ & $-4.356 * * *$ & $(0.307)$ & $-6.377 * * *$ & $(0.919)$ & $-6.925 * * *$ & $(0.497)$ & -20.843 & (18.409) \\
\hline $3-4$ & $-4.181 * * *$ & $(0.304)$ & $-6.077 * * *$ & $(0.731)$ & $-4.812 * * *$ & $(0.371)$ & -19.453 & (18.371) \\
\hline $5-8$ & $-4.124 * * *$ & $(0.306)$ & $-5.936 * * *$ & $(0.647)$ & $-4.682 * * *$ & $(0.362)$ & -19.023 & (18.368) \\
\hline $9-16$ & $-4.033 * * *$ & $(0.311)$ & $-6.092 * * *$ & $(0.612)$ & $-5.124 * * *$ & $(0.363)$ & -19.509 & $(18.366)$ \\
\hline $17-30$ & $-3.851 * * *$ & $(0.316)$ & $-5.687 * * *$ & $(0.566)$ & $-5.403 * * *$ & $(0.365)$ & -19.334 & (18.368) \\
\hline $31-52$ & $-4.396 * * *$ & $(0.336)$ & $-5.530 * * *$ & $(0.553)$ & $-4.775 * * *$ & $(0.367)$ & -19.436 & (18.367) \\
\hline 52 or more & $-4.805 * * *$ & $(0.308)$ & $-5.406 * * *$ & $(0.532)$ & $-5.806 * * *$ & $(0.373)$ & -19.841 & (18.368) \\
\hline \multicolumn{9}{|c|}{ Unobserved heterogeneity } \\
\hline \multicolumn{9}{|l|}{$n u_{1}$} \\
\hline$n u_{2}$ & $1.463 * * *$ & $(0.246)$ & $-1.976 * *$ & $(0.894)$ & $-0.593 *$ & $(0.333)$ & 11.014 & $(18.352)$ \\
\hline$P\left(n u=n u_{1}\right)$ & $2.053 * * *$ & $(0.425)$ & & & & & & \\
\hline
\end{tabular}


Table 9: Estimation results with 3 states - women

\begin{tabular}{|c|c|c|c|c|c|c|c|c|}
\hline \multirow{3}{*}{ Assignment to treatn } & \multicolumn{4}{|c|}{ From Unemployment to } & \multicolumn{4}{|c|}{ From Employment to } \\
\hline & \multicolumn{2}{|c|}{ Employment } & \multicolumn{2}{|c|}{ Inactivity } & \multicolumn{2}{|c|}{ Unemployment } & \multicolumn{2}{|c|}{ Inactivity } \\
\hline & ent group & & & & & & & \\
\hline$\delta * 1(t<30)$ & $0,196 * * *$ & $(0,060)$ & $0,383 * * *$ & $(0,146)$ & & & & \\
\hline$\delta * 1(t>30)$ & $-0,079$ & $(0,125)$ & 0,084 & $(0,205)$ & & & & \\
\hline$\delta$ & & & & & $-0,033$ & $(0,080)$ & $-0,007$ & $(0,095)$ \\
\hline Southern Jutland & $-0,103 *$ & $(0,056)$ & $-0,043$ & $(0,119)$ & $-0,092$ & $(0,081)$ & 0,134 & $(0,095)$ \\
\hline Married & $0,101 *$ & $(0,061)$ & $0,315 * *$ & $(0,132)$ & $-0,212 * *$ & $(0,088)$ & 0,093 & $(0,109)$ \\
\hline \multicolumn{9}{|c|}{ Share of time on public income transfer } \\
\hline in previous year & $-0,418 * * *$ & $(0,100)$ & $-0,058$ & $(0,190)$ & $0,354 * *$ & $(0,143)$ & $0,408 * * *$ & $(0,160)$ \\
\hline $1-2$ years ago & 0,014 & $(0,110)$ & $0,369 *$ & $(0,217)$ & 0,079 & $(0,166)$ & 0,268 & $(0,188)$ \\
\hline $2-3$ years ago & $-0,034$ & $(0,089)$ & 0,007 & $(0,188)$ & 0,128 & $(0,141)$ & $-0,208$ & $(0,158)$ \\
\hline \multicolumn{9}{|c|}{ UI fund (ref.: manufacturing) } \\
\hline construction & $0,632 * * *$ & $(0,175)$ & 0,428 & $(0,509)$ & $-0,349$ & $(0,316)$ & 0,063 & $(0,297)$ \\
\hline metal & $-0,384$ & $(0,796)$ & 0,925 & $(0,887)$ & 0,519 & $(0,730)$ & 0,410 & $(1,105)$ \\
\hline technicians & $-0,006$ & $(0,191)$ & $-0,223$ & $(0,483)$ & $-0,537$ & $(0,346)$ & $-0,012$ & $(0,279)$ \\
\hline trade & $-0,249 * * *$ & $(0,091)$ & 0,043 & $(0,193)$ & 0,054 & $(0,134)$ & $-0,118$ & $(0,161)$ \\
\hline funk & 0,044 & $(0,095)$ & 0,070 & $(0,212)$ & $-0,295 * *$ & $(0,141)$ & $-0,085$ & $(0,157)$ \\
\hline academics & $-0,115$ & $(0,210)$ & 0,053 & $(0,452)$ & 0,136 & $(0,247)$ & 0,157 & $(0,311)$ \\
\hline self-employed & $-0,612 * * *$ & $(0,153)$ & 0,173 & $(0,291)$ & 0,287 & $(0,207)$ & $-0,034$ & $(0,286)$ \\
\hline other & $-0,121$ & $(0,082)$ & 0,066 & $(0,182)$ & $0,292 * *$ & $(0,114)$ & 0,024 & $(0,144)$ \\
\hline \multicolumn{9}{|l|}{ Age (ref.: 30-39) } \\
\hline below 24 & $0,231 * *$ & $(0,105)$ & $0,389 *$ & $(0,222)$ & $-0,212$ & $(0,169)$ & $0,338 * *$ & $(0,168)$ \\
\hline $25-29$ & $-0,001$ & $(0,093)$ & $0,486 * * *$ & $(0,164)$ & $-0,029$ & $(0,139)$ & 0,128 & $(0,141)$ \\
\hline $40-49$ & $-0,059$ & $(0,076)$ & $-0,509 * * *$ & $(0,182)$ & $0,223 * *$ & $(0,111)$ & $-0,511 * * *$ & $(0,133)$ \\
\hline above 50 & $-0,445 * * *$ & $(0,082)$ & $-0,193$ & $(0,170)$ & $0,572 * * *$ & $(0,113)$ & $-0,220$ & $(0,143)$ \\
\hline \multicolumn{9}{|c|}{ Nationality (ref.: Danish) } \\
\hline Western immigrant & $-0,175$ & $(0,158)$ & 0,131 & $(0,334)$ & 0,072 & $(0,224)$ & $-0,134$ & $(0,321)$ \\
\hline Non-western immigrant & $-0,316 * *$ & $(0,126)$ & $-0,361$ & $(0,252)$ & $0,342 * *$ & $(0,168)$ & $-0,449 *$ & $(0,266)$ \\
\hline \multicolumn{9}{|c|}{ Week of entry into the experiment } \\
\hline $3-4$ & 0,086 & $(0,128)$ & $-0,374$ & $(0,254)$ & & & & \\
\hline $5-6$ & 0,066 & $(0,103)$ & $-0,330$ & $(0,209)$ & & & & \\
\hline $7-8$ & 0,072 & $(0,150)$ & $-0,053$ & $(0,289)$ & & & & \\
\hline $9-10$ & $0,223 * * *$ & $(0,084)$ & $-0,285$ & $(0,178)$ & & & & \\
\hline $11-12$ & 0,104 & $(0,113)$ & 0,044 & $(0,214)$ & & & & \\
\hline $13-14$ & 0,094 & $(0,096)$ & $-0,173$ & $(0,190)$ & & & & \\
\hline $15-17$ & $0,190 *$ & $(0,105)$ & $-0,457 *$ & $(0,237)$ & & & & \\
\hline \multicolumn{9}{|c|}{ Lagged unemployment duration (ref.: below 6 weeks) } \\
\hline $6-8$ & & & & & $-0,075$ & $(0,156)$ & $-0,139$ & $(0,177)$ \\
\hline $9-16$ & & & & & 0,105 & $(0,116)$ & $-0,027$ & $(0,141)$ \\
\hline $17-28$ & & & & & $0,200 *$ & $(0,122)$ & $-0,099$ & $(0,154)$ \\
\hline $29-52$ & & & & & $-0,107$ & $(0,139)$ & $-0,114$ & $(0,170)$ \\
\hline \multicolumn{9}{|c|}{ Baseline hazard (in weeks) } \\
\hline $0-1$ & $-3,361 * * *$ & $(0,176)$ & $-5,299 * * *$ & $(0,423)$ & $-0,503 * * *$ & $(0,180)$ & 0,129 & $(0,183)$ \\
\hline $1-2$ or $0-2$ & $-3,053 * * *$ & $(0,162)$ & $-6,505 * * *$ & $(0,561)$ & $-5,113 * * *$ & $(0,260)$ & $-7,042 * * *$ & $(0,622)$ \\
\hline $3-4$ & $-3,354 * * *$ & $(0,145)$ & $-5,680 * * *$ & $(0,378)$ & $-4,078 * * *$ & $(0,209)$ & $-5,026 * * *$ & $(0,300)$ \\
\hline $5-8$ & $-3,240 * * *$ & $(0,131)$ & $-5,558 * * *$ & $(0,322)$ & $-4,382 * * *$ & $(0,195)$ & $-5,283 * * *$ & $(0,273)$ \\
\hline $9-16$ & $-2,925 * * *$ & $(0,123)$ & $-5,081 * * *$ & $(0,280)$ & $-4,930 * * *$ & $(0,196)$ & $-5,496 * * *$ & $(0,262)$ \\
\hline $17-30$ & $-3,032 * * *$ & $(0,124)$ & $-5,035 * * *$ & $(0,281)$ & $-5,210 * * *$ & $(0,200)$ & $-5,538 * * *$ & $(0,247)$ \\
\hline $31-52$ & $-3,296 * * *$ & $(0,145)$ & $-4,807 * * *$ & $(0,286)$ & $-4,919 * * *$ & $(0,190)$ & $-5,485 * * *$ & $(0,232)$ \\
\hline 52 or more & $-3,339 * * *$ & $(0,146)$ & $-4,945 * * *$ & $(0,298)$ & $-6,625 * * *$ & $(0,195)$ & $-5,748 * * *$ & $(0,210)$ \\
\hline
\end{tabular}

Note: * indicates statistical significance at the $10 \%$ level, $* *$ at the $5 \%$ level, and $* * *$ at the $1 \%$ level. 